\title{
The Internal Generation of the Atlantic Ocean Interdecadal Variability
}

\author{
Olivier Arzel, Thierry Huck, AND Alain COlin De Verdière \\ Laboratoire d'Océanographie Physique et Spatiale, Université de Bretagne Occidentale, Brest, France
}

(Manuscript received 21 December 2017, in final form 7 May 2018)

\begin{abstract}
Numerical simulations of a realistic ocean general circulation model forced by prescribed surface fluxes are used to study the origin and structure of intrinsic interdecadal variability of the ocean circulation. When eddyinduced turbulent diffusivities are low enough, spontaneous oscillations of the Atlantic meridional overturning circulation (AMOC) with periods $O(20) \mathrm{yr}$ and amplitude $O(1) \mathrm{Sv}\left(1 \mathrm{~Sv} \equiv 10^{6} \mathrm{~m}^{3} \mathrm{~s}^{-1}\right)$ emerge. The transition from the steady to the oscillatory regime is shown to be consistent with a supercritical Hopf bifurcation of the horizontal Peclet number. Adding atmospheric thermal damping is shown to have a very limited influence on the domain of existence of intrinsic variability. The spatial structure of the mode consists of a dipole of sea surface temperature (SST)/sea surface height (SSH) anomalies centered at about $50^{\circ} \mathrm{N}$ with stronger variance in the western part of the subpolar gyre, in agreement with the observed Atlantic multidecadal oscillation (AMO) signature in this region. Specific features include a westward propagation of temperature anomalies from the source region located on the western flank of the North Atlantic Current (NAC) and a one-quarter phase lag between surface and subsurface $(800 \mathrm{~m})$ temperature anomalies. Local linear stability calculations including viscous and diffusive effects confirm that the North Atlantic Current is baroclinically unstable on scales of $O(1000) \mathrm{km}$ with growth rates of $O(1) \mathrm{yr}^{-1}$. Both the spatial structure of the mode and the period agree in magnitude with in situ measurements in the North Atlantic, suggesting that this intrinsic ocean mode participates in the observed Atlantic bidecadal climate variability.
\end{abstract}

\section{Introduction}

Analyses of observations over the instrumental era show a pronounced multidecadal variability in the North Atlantic, with alternating basinwide warming and cooling phases with a dominant time scale of 60-90 yr (Schlesinger and Ramankutty 1994; Enfield et al. 2001). This mode of variability, referred to as the Atlantic multidecadal oscillation (AMO) or Atlantic multidecadal variability (AMV), explains nearly $40 \%$ of the total integrated annual mean sea surface temperature (SST) variance over the basin (Delworth et al. 2007). These low-frequency variations are associated with changes in African Sahel rainfall, Atlantic hurricanes, and North American and European summer climate (Knight et al. 2006). Multiproxy-based reconstructions show that this natural mode of variability has existed before the instrumental era, with periodicities spanning the 50-70-yr range over the past millennia (Knudsen et al. 2011). Shorter time scales in the range of 20-30 yr have also been reported in a variety of observations, based on either multiproxy analyses

Corresponding author: Olivier Arzel, olivier.arzel@univ-brest.fr
(Chylek et al. 2011) or direct measurements of tide gauge records around the North Atlantic (Frankcombe and Dijkstra 2009).

The fluctuations of North Atlantic SST associated with the AMO form the classical horseshoe-shaped pattern that consists in an SST anomaly of one sign extending from the subpolar gyre to the tropics, and an anomaly of opposite sign in the western subtropical gyre (Kushnir 1994; Deser et al. 2010). SST changes are maximum in the western part of the subpolar gyre and weaker in the tropics and in the subtropical area. What determines the spatiotemporal structure of this natural mode of variability and whether the ocean or the atmosphere primarily drives the variability remains controversial. The instrumental record is unfortunately too sparse in terms of spatial coverage and too short compared to the time scales of the variability to address these questions. In addition, the observational record cannot provide the North Atlantic SST response to anthropogenic and aerosols forcings needed to disentangle the forced response from the intrinsic variability (Knight 2009). Consequently, progress in both the determination and understanding of the North Atlantic interdecadal 
variability comes mostly from studies based on numerical models, either idealized or fully coupled and realistic. As a whole, these studies are inconclusive about the respective role of the ocean and the atmosphere for the AMO because of the large diversity of the proposed mechanisms and the comparisons of the patterns and time scales of the variability with observations. Two strong paradigms emerged: 1) the first one is related to the integration of the atmospheric white noise by the ocean along with its large heat capacity giving rise to a reddened spectrum (Hasselmann 1976); and 2) the second one has dynamical origins and is related to intrinsic unstable interdecadal ocean modes that spontaneously develop under steady surface buoyancy fluxes, a hypothesis that has only been tested in models ranging in complexity from idealized to intermediate (Greatbatch and Zhang 1995; Colin de Verdière and Huck 1999; te Raa and Dijkstra 2002; Arzel et al. 2007; Jamet et al. 2016).

The debate has recently been reinvigorated following the study of Clement et al. (2015), who compared outputs of a suite of coupled models as part of phase 3 of the Coupled Model Intercomparison Project (CMIP3) and atmospheric models coupled to slab-ocean mixed layer components without ocean dynamics. The observed AMO pattern is well reproduced and remarkably similar in both fully coupled and slab-ocean models, leading the authors to conclude that the AMO does not rely on ocean circulation changes but is rather a consequence of the integration by the ocean of short-term atmospheric fluctuations embodied in the NAO, thereby supporting the first paradigm. Theoretical spectra based on stochastically forced conceptual models (Barsugli and Battisti 1998) show a flattening of the spectra at low frequencies as a result of the large heat capacity of the ocean compared to that of the atmosphere. Observational spectra of midlatitude temperature anomalies fail to flatten into a white spectrum at long time scales, but instead continue to redden (Dommenget and Latif 2002), suggesting a possible role of ocean dynamics at these latitudes. This view is supported by observations and results from realistic coupled models (Gulev et al. 2013; Zhang et al. 2016; O'Reilly et al. 2016), which show that midlatitude SST changes and (turbulent) surface heat flux anomalies (positive downward) are negatively correlated on decadal time scales, indicating that dynamical ocean processes are essential in producing variance on these time scales. Cane et al. (2017) used a simple red noise model to interpret this negative correlation as the result of negligible ocean forcing, with the atmospheric stochastic forcing being the main driver of the AMV. Zhang (2017) resolved the controversy and showed that adding oceanic damping in the red noise model of Cane et al. (2017) brings back the oceanic forcing as the main driver of low-frequency subpolar North Atlantic SST anomalies associated with the AMV.

In addition to the atmospheric white noise that certainly plays a role, a number of studies based on standalone ocean models have demonstrated the unstable character of the ocean circulation on interdecadal time scales. This is the second paradigm: the variability originates from an instability internal to the ocean circulation itself, without the need for time-varying surface fluxes or coupling with the atmosphere. When these intrinsic ocean modes are damped rather than selfsustained, for example when the lateral eddy diffusion is beyond a critical threshold, the addition of a small amount of atmospheric noise can be sufficient for the variability to emerge with resonant frequencies characteristic of the damped ocean mode. Examples of such a noise-induced oceanic interdecadal variability can be found in Herbaut et al. (2002), Dong and Sutton (2005), or Frankcombe et al. (2009).

The existence of intrinsic interdecadal modes of the overturning circulation was first shown in idealized ocean models forced by prescribed and steady surface fluxes (Greatbatch and Zhang 1995; Huck et al. 1999; te Raa and Dijkstra 2002; Arzel et al. 2006). Although very idealized, these models capture several aspects of the observed North Atlantic low-frequency variability. These aspects include in particular a westward propagation of midlatitude temperature signals (Feng and Dijkstra 2014) and a one-quarter phase lag between surface and subsurface temperature anomalies (Frankcombe et al. 2008). The emerging periodicities remain within the interdecadal band (20-30yr) and depend on the choice of forcing characteristics and mixing parameters. The internal mode has proven to be robust to the presence of mesoscale turbulence (Huck et al. 2015) and coupling with a hierarchy of atmospheric components (Chen and Ghil 1996; Huck et al. 2001; Arzel et al. 2007; Jamet et al. 2016). In addition, the sensitivity of the properties of interdecadal oscillations of the meridional overturning circulation to horizontal turbulent eddy diffusivities has also been studied extensively (Huck et al. 1999; Colin de Verdière and Huck 1999). Because these sensitivity studies are based on numerical models with either simplified physics [e.g., planetary geostrophic dynamics, linear equation of state, or use of horizontal eddy diffusivity instead of along-isopycnal mixing that produces the so-called Veronis effect (Veronis 1975) where an unphysically large downwelling occurs in the ocean interior] or idealized geometries (e.g., mostly flat bottoms and singlehemispheric sectors of the sphere), the relevance of this internal ocean mode for the observed low-frequency variability remains untested. We extend these sensitivity studies to a higher level in the hierarchy of complexity 
following Held (2005) by using a realistic geometry (continental boundaries and ocean bathymetry), which may significantly alter the domain of existence of the variability identified with lower levels of complexity. The effect of bottom topography for instance is not robust across models: while intrinsic interdecadal modes are completely damped out in the study of Winton (1997), they survive in the study of te Raa et al. (2004), suggesting that the details of the model configuration and choice of forcing and/or parameters are critical in determining the response of the system. Ferjani et al. (2013) showed that the direct effect of bottom topography on mode characteristics is quite limited and suggested instead that changes in the mean flow structure resulting from bottom topography may have more influence. Given the importance of the mean flow structure for the development of intrinsic oceanic interdecadal modes (Huck and Vallis 2001), it is necessary to pursue the sensitivity studies in more realistic contexts than those previously used. By contrast to previous works that used horizontal eddy diffusivity as the control parameter, the sensitivity analysis we propose here is based on the more physically relevant eddy-induced and isopycnal mixing parameters. Within this framework we aim to determine the range of turbulent eddy diffusivity values for which spontaneous interdecadal oscillations of the Atlantic circulation emerge. The variability is shown to exist for eddy-induced diffusivity values lower than those traditionally used in realistic coupled models, implying that some noise excitation would be required for these intrinsic oceanic modes to emerge in such models.

The objective of this paper is to test the hypothesis that internal generation of interdecadal variability of the ocean circulation may be relevant to explain North Atlantic climate variability. To this end we use a realistic ocean general circulation model (OGCM) forced by prescribed surface fluxes of heat, freshwater, and momentum, and assess the ability of the Atlantic circulation to exhibit self-sustained oscillations on interdecadal time scales. This modeling study uses a realistic geometry, a model configuration that sharply contrasts with previous studies on the same kind based on idealized geometries. The surface boundary condition remains idealized in the sense that it does not include any coupling with the atmosphere, but as will be shown, adding atmospheric thermal damping with realistic $e$-folding times has a limited impact on the variability. The paper explores the signature and the physics of intrinsic oceanic modes that have been suggested to play a significant role in realistic model studies (Muir and Fedorov 2017). We assess the robustness of the interdecadal modes found previously in these idealized models, explore the nature of the transition from the steady to the oscillatory regime, the mechanism of the variability, its pattern, and its origin. This study therefore puts the conclusions obtained with these idealized models in a more realistic context, which is a necessary step up in the model hierarchy. The difficulty to extract the cause of the events in realistic coupled models is the reason why a model hierarchy-based approach is necessary.

The paper is structured as follows. Section 2 describes the model and the experimental design. The sensitivity of the internally generated interdecadal variability to eddy-induced and isopycnal mixing coefficients is presented in section 3 . Section 4 provides a description of the structure of the mode including both its horizontal and vertical structure. In section 5, a local linear stability calculation including dissipative effects supports the baroclinically unstable character of the North Atlantic Current with growth rates of $O(1) \mathrm{yr}^{-1}$ and scales of $O(1000) \mathrm{km}$. The paper finally concludes with a summary and a discussion in section 6 .

\section{Model description, methodology, and model climatology}

\section{a. The model}

We use the MITgcm (Marshall et al. 1997) run at $1^{\circ}$ horizontal resolution. The World Ocean model domain extends from $80^{\circ} \mathrm{S}$ to $80^{\circ} \mathrm{N}$, with vertical walls at those latitudinal boundaries. There are 44 levels on the vertical with grid spacing increasing from $10 \mathrm{~m}$ at the surface to $250 \mathrm{~m}$ at the bottom. Static instability is removed by strong mixing of the water column with a vertical diffusivity coefficient of $100 \mathrm{~m}^{2} \mathrm{~s}^{-1}$. The vertical diffusivity $k_{v}$ increases downward following a Bryan and Lewis (1979) vertical profile with upper and bottom values of 0.5 and $1.3 \times 10^{-4} \mathrm{~m}^{2} \mathrm{~s}^{-1}$, respectively. These values are in line with those inferred from large-scale inversion experiments (Lumpkin and Speer 2007), direct measurements (Waterhouse et al. 2014) and more recent robust diagnostic calculations (Arzel and Colin de Verdière 2016). We use a spatially uniform horizontal Laplacian viscosity $\nu_{h}$ of $5 \times 10^{4} \mathrm{~m}^{2} \mathrm{~s}^{-1}$, which is sufficient to resolve the frictional boundary layer, whose width is given by $(2 \pi / \sqrt{3})\left(\nu_{h} / \beta\right)^{1 / 3}$ (Pedlosky 1987). The Gent-McWilliams (GM) parameterization (Gent and McWilliams 1990) of mesoscale eddies is implemented along with the rotated eddy diffusion tensor for isopycnal mixing (Redi 1982). A parameter sensitivity analysis in terms of these mixing coefficients is carried out (Table 1). A second order-centered advection scheme for tracers is used. While being highly dispersive, this scheme has the advantage of conserving the 
TABLE 1. Summary of experiments designed to assess the sensitivity of the model solution to $K$ and $K_{\mathrm{GM}}$. Experiments using spatially varying $K_{\mathrm{GM}}$ coefficients, based on the Visbeck et al. (1997)'s parameterization, require the maximum value reached by $K_{\mathrm{GM}}$ to be specified (indicated by asterisks). The sensitivity to isopycnal mixing is performed for two values of $K_{\mathrm{GM}}$. The reference experiment uses $K=1000 \mathrm{~m}^{2} \mathrm{~s}^{-1}$ and $K_{\mathrm{GM}}=550 \mathrm{~m}^{2} \mathrm{~s}^{-1}$.

\begin{tabular}{lccc}
\hline \hline & Thermal damping & $K\left(\mathrm{~m}^{2} \mathrm{~s}^{-1}\right)$ & $K_{\mathrm{GM}}\left(\mathrm{m}^{2} \mathrm{~s}^{-1}\right)$ \\
\hline Control run & No & 1000 & 550 \\
Sensitivity to $K_{\mathrm{GM}}$ & No & 1000 & $200,300,400,500^{*}, 512.5,525,537.5$, \\
& & $550,562.5,575,587.5,600$, and $1000^{*}$ \\
Sensitivity to $K_{\mathrm{GM}}$ & Yes & 1000 & $200,300,400,500,525,550,562.5,575$, \\
& No & $500,750,1000,1250$, & 587.5, and 600 \\
Sensitivity to $K$ & & 1500, and 2000 & 500 and 550 \\
& &
\end{tabular}

first and second moments (mean and variance, respectively), as well as limiting the production of spurious diapycnal mixing as long as the Munk boundary layer is resolved (Griffies et al. 2000). The equation of state (JMDZ95) is that proposed by Jackett and McDougall (1995), which computes the in situ density from potential temperature (the temperature variable in the model), practical salinity, and Boussinesq hydrostatic pressure. Ocean bathymetry is taken from the historical 1-arc-min gridded bathymetry for the world (ETOPO1) dataset (Amante and Eakins 2009) interpolated onto the model grid using a simple Gaussian filter with a width of $100 \mathrm{~km}$. The model uses a seasonal wind stress (Large and Yeager 2009) averaged over the years 1949-2006.

\section{b. Experimental design}

We use flux boundary conditions at the surface for both temperature and salinity in our ocean-only experiments. A flux formulation is justified for salinity because of the absence of feedback between sea surface salinity (SSS) and freshwater flux. The justification for temperature is more difficult because a fraction of the surface buoyancy flux (turbulent heat fluxes, evaporation, longwave radiation) depends on SST. On time scales much longer than the atmospheric spindown time scale $\rho_{a} C_{\mathrm{pa}} H_{a} / \lambda=O(10)$ days (with $\rho_{a}$ the atmospheric density, $C_{\mathrm{pa}}$ the specific heat of dry air, $H_{a}$ the atmospheric scale height, and $\lambda$ the surface heat flux feedback), the heat capacity resides in the ocean and the atmosphere becomes slaved to changes in ocean circulation. In this limiting case the surface boundary condition on temperature reduces to a weak damping on SST anomalies. Vallis (2009) estimates this damping rate to be $O(1 / 1600)$ days $^{-1}\left(\sim 4.4 \mathrm{yr}^{-1}\right)$, which is on the same order as a typical $e$-folding time of perturbations found in models forced by prescribed surface fluxes (Huck et al. 2001). However, characteristics of the variability in coupled models are very similar to those obtained under climatological forcing diagnosed from the coupled simulation (Arzel et al. 2007; Zhu and Jungclaus 2008;
Jamet et al. 2016). This indicates, at least in those specific cases, that the flux formulation captures the essential behavior of low-frequency air-sea interactions. The standard experiments discussed in this paper therefore use prescribed surface buoyancy fluxes. As will be shown, adding a realistic thermal damping with a time scale of $1 \mathrm{yr}$ to the prescribed surface heat flux has a limited impact on the variability.

Surface buoyancy fluxes are diagnosed from a model integration under restoring boundary conditions rather than prescribed from observations, in a similar manner as Arzel et al. (2007) and Frankcombe et al. (2009). This procedure allows the perturbations in the flux boundary condition experiments to grow from an equilibrium state obtained under restoring boundary conditions, leading to a straightforward relationship between the characteristics of the variability and the structure of this equilibrium state. Thermal damping, when included, is computed by restoring the SST under flux boundary conditions toward the observed annual mean SST field (Locarnini et al. 2010) with a time scale of $1 \mathrm{yr}$.

The sensitivity to the GM coefficient $K_{\mathrm{GM}}$ is explored here through a set of 14 experiments (keeping isopycnal mixing $K=1000 \mathrm{~m}^{2} \mathrm{~s}^{-1}$ in all runs) spanning the 200 $600 \mathrm{~m}^{2} \mathrm{~s}^{-1}$ range (Table 1). Twelve of these experiments use a spatially uniform coefficient and two of them use the Visbeck et al. (1997) formulation that allows $K_{\mathrm{GM}}$ to vary with the Eady growth rate. The sensitivity to isopycnal turbulent diffusivity $K$ is explored through a set of 12 experiments, spanning the $500-2000 \mathrm{~m}^{2} \mathrm{~s}^{-1}$ range, for two fixed values of $K_{\mathrm{GM}}$, namely, 500 and $550 \mathrm{~m}^{2} \mathrm{~s}^{-1}$. The sensitivity analysis is thus made around the pivot or reference experiment using $K=1000 \mathrm{~m}^{2} \mathrm{~s}^{-1}$ and $K_{\mathrm{GM}}=$ $550 \mathrm{~m}^{2} \mathrm{~s}^{-1}$

For each set of mixing parameters $K$ and $K_{\mathrm{GM}}$, the model is first brought to equilibrium through relaxation of SST and SSS fields toward the World Ocean Atlas climatology (Locarnini et al. 2010; Antonov et al. 2010). The restoring procedure occurs on a monthly time scale in order to mimick seasonal variations of the surface 
a) $\mathrm{AMOC}(\mathrm{Sv})$

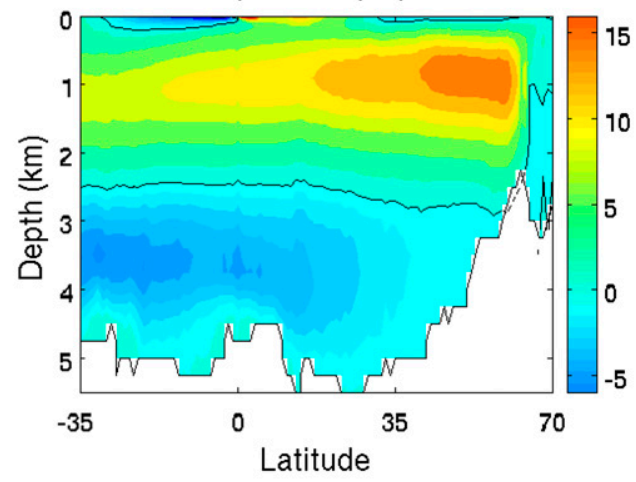

c) Barotropic Streamfunction (Sv)

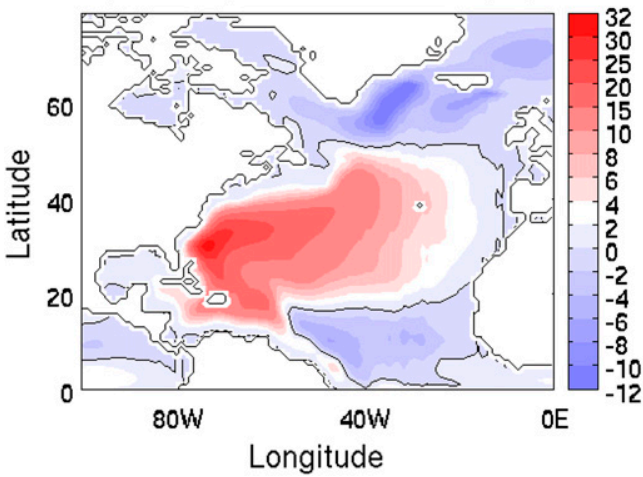

b) March Mixed Layer Depth (m)

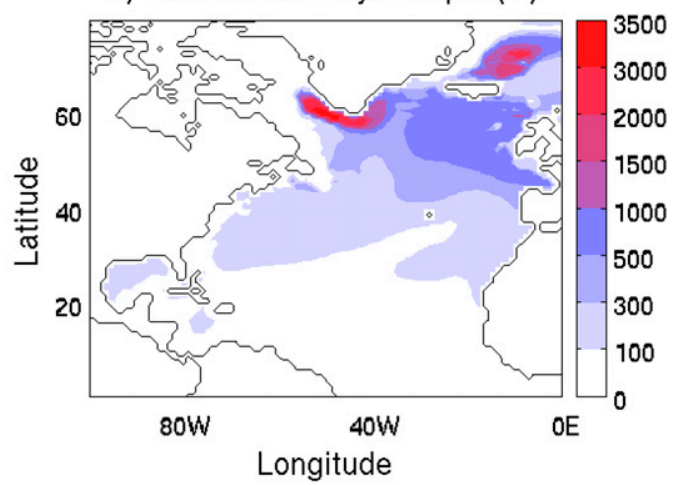

d) $\mathrm{SSH}(\mathrm{m})$ and upper ocean currents

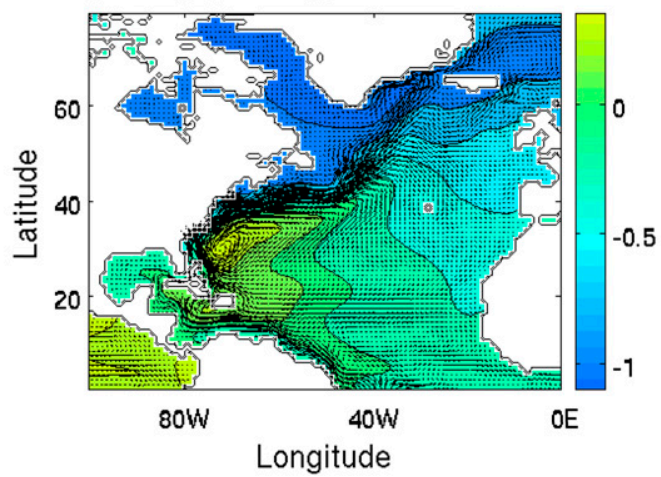

FIG. 1. North Atlantic Ocean state diagnosed over years 1201-1400 of the reference FTFS experiment ( $K=1000 \mathrm{~m}^{2} \mathrm{~s}^{-1}$ and $K_{\mathrm{GM}}=550 \mathrm{~m}^{2} \mathrm{~s}^{-1}$ ). (a) AMOC (Sv) with the zero contour line (black), (b) March mixed layer depth $(\mathrm{m}),(\mathrm{c})$ barotropic streamfunction (Sv) with the zero contour line (black), and (d) ocean currents in the upper $250 \mathrm{~m}$ and SSH $(\mathrm{m})$.

buoyancy flux. The temperature- and salinity-restoring time scales (both uniform in space and time) have been adjusted to produce a model solution (under restoring boundary conditions) as close as possible to observations in terms of both circulation (Lumpkin and Speer 2007) and surface buoyancy fluxes (Large and Yeager 2009). The best compromise that emerged from a number of trials was to choose a restoring time scale of 10 days for SST, which corresponds to an air-sea turbulent heat transfer coefficient of about $40 \mathrm{~W} \mathrm{~m}^{-2} \mathrm{~K}^{-1}$ for an upperlayer thickness of $10 \mathrm{~m}$. This value is in the range of observed surface heat flux sensitivities, which were estimated to be in the range $10-50 \mathrm{~W} \mathrm{~m}^{-2} \mathrm{~K}^{-1}$ depending on seasons and geographical location (Frankignoul et al. 2004). A longer time scale of 6 months is used for SSS, consistent with the absence of feedback between SSS and the freshwater flux. These experiments, termed restoring temperature and restoring salinity (RTRS), start from the same initial condition corresponding to the end state of a previous $6000-\mathrm{yr}$ model integration. Each RTRS run is 1200-yr long, which is sufficient to reach a new equilibrium. Monthly mean surface heat and freshwater fluxes are diagnosed over the last year of each RTRS run to form a synthetic seasonal cycle. Averaging over the last year of the experiments is justified since internal variability is totally absent in these runs (mesoscale turbulence does not appear at this coarse horizontal resolution). This synthetic seasonal forcing is then applied repetitively to the ocean surface for a further model run, named prescribed flux for temperature and salinity (FTFS), whose length (typically $>1000 \mathrm{yr}$ ) is adjusted to yield reasonable stationary statistics. The goal of the paper is to discuss the physics of interdecadal modes that develop in these experiments.

\section{c. Model climatology}

Figure 1 shows the mean ocean circulation state diagnosed over years 1201-1400 of the reference experiment (FTFS experiment with $K_{\mathrm{GM}}=550 \mathrm{~m}^{2} \mathrm{~s}^{-1}$ and $K=$ $\left.1000 \mathrm{~m}^{2} \mathrm{~s}^{-1}\right)$. Both the spatial structure and strength of the Atlantic meridional overturning circulation (AMOC) are consistent with hydrographic data (Lumpkin and Speer 2007) with a $16 \mathrm{~Sv}\left(1 \mathrm{~Sv} \equiv 10^{6} \mathrm{~m}^{3} \mathrm{~s}^{-1}\right)$ North Atlantic Deep Water (NADW) cell in the upper $2500 \mathrm{~m}$ and a weaker (5 Sv) Antarctic Bottom Water cell below (Fig. 1a). NADW formation occurs in the northern part of the 
a) $\mathrm{AMOC}$

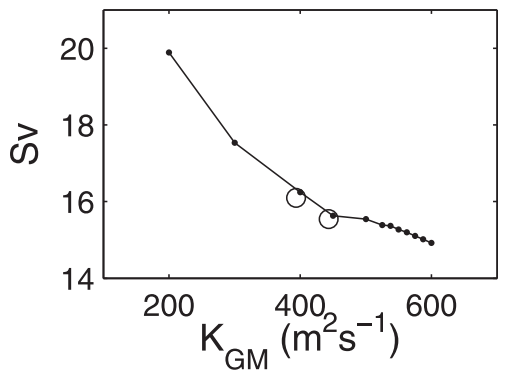

b) $\mathrm{AMOC}$

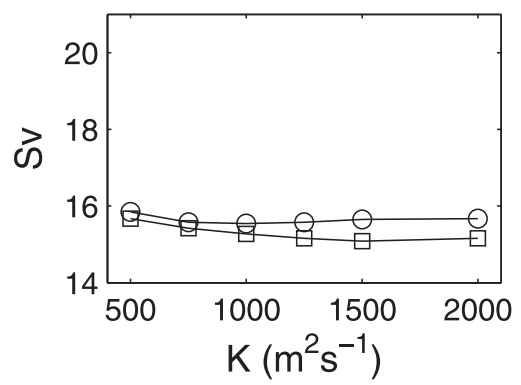

c) AMV index

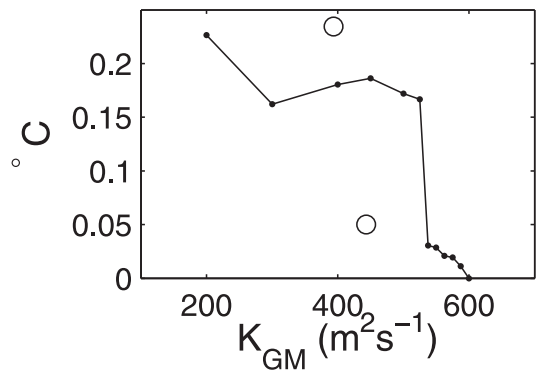

d) AMV index

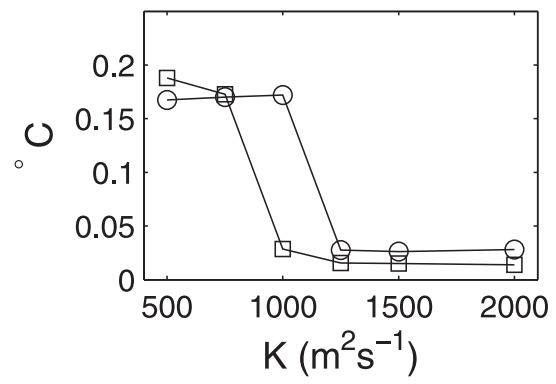

e) Period

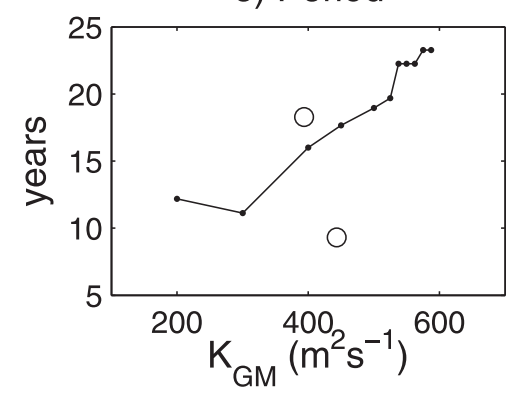

f) Period

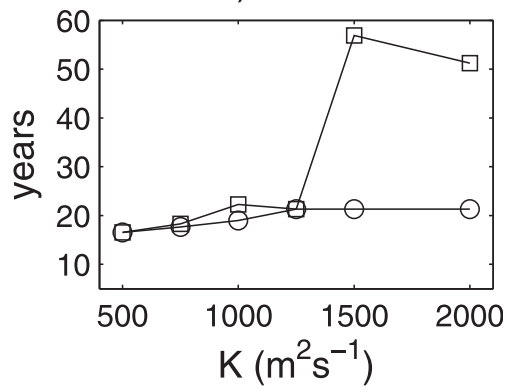

FIG. 2. Sensitivity of the model solutions to (a),(c),(e) $K_{\mathrm{GM}}$ and (b),(d),(f) $K$ : (left) mean strength of the AMOC computed as the maximum strength of the meridional overturning streamfunction below $1000 \mathrm{~m}$ and north of $30^{\circ} \mathrm{N}$, (center) AMV index computed as the peak-to-peak amplitude of the area-weighted North Atlantic SST anomalies using a high-pass filter with a cutoff frequency of $1 / 100 \mathrm{yr}^{-1}$, and (right) dominant period estimated from a multitaper spectral analysis of the basin mean kinetic energy density time series of the North Atlantic. The sensitivity to $K$ in (b),(d),(f) has been evaluated for $K_{\mathrm{GM}}=500$ (circles) and $550 \mathrm{~m}^{2} \mathrm{~s}^{-1}$ (squares). The two circles in each of (a),(c),(e) indicate the statistics obtained for the experiments using the Visbeck et al. (1997) formulation. For those specific cases the GM diffusivities used to build the individual plots have been averaged in region of maximum SST variance. Note the different vertical scales for the oscillation period in (e) and (f).

Labrador Sea and in the Greenland-Iceland-Norwegian Seas (Fig. 1b), consistent with observations, although convective mixing seems excessively deep (de Boyer Montégut et al. 2004). The barotropic transports (Fig. 1c) are underestimated compared to observations (Colin de Verdière and Ollitrault 2016), a bias that is related to the low resolution of the model that does not permit mesoscale turbulence. The Gulf Stream remains attached to the coast (Fig. 1d), presumably because of the absence of the Northern Recirculation Gyre (Fig. 1c) usually observed between Cape Hatteras and the Grand Banks (Zhang and Vallis 2007). After passing the Grand Banks, the Gulf Stream continues too far north of the North Atlantic Current instead of veering more to the east, a common problem in low-resolution circulation studies (Denng et al. 1996).

\section{Parameter sensitivity analysis}

The results of this sensitivity analysis are summarized in Figs. 2 and 3. The readers interested in the description of the variability may skip this section.

\section{a. Sensitivity to thickness diffusivity $K_{G M}$}

Figure 2a shows that the AMOC strength decreases by $25 \%$, from 20 to $15 \mathrm{~Sv}$, as $K_{\mathrm{GM}}$ is varied between 200 and $600 \mathrm{~m}^{2} \mathrm{~s}^{-1}$. Marshall et al. (2017) interpreted those changes in terms of scaling laws and invoked the central role of the Southern Ocean in interhemispheric dynamics. Interdecadal variability disappears for thickness diffusivities $K_{\mathrm{GM}}$ larger than about $600 \mathrm{~m}^{2} \mathrm{~s}^{-1}$, that is, for an overturning strength $(15 \mathrm{~Sv})$ that is comparable to that observed today. This critical diffusivity value is associated with a nondimensional Peclet number $(\mathrm{Pe}=$ $\left.U \Delta x / K_{\mathrm{GM}}\right)$ of 1.31 , where $U=1 \mathrm{~cm} \mathrm{~s}^{-1}$ is a scale for horizontal velocity and $\Delta x=75 \mathrm{~km}$ approximately corresponds to the model horizontal grid size at midlatitudes. The amplitude of oscillations (as measured by the peak-to-peak amplitude of basin mean kinetic energy density in the North Atlantic) in the vicinity of this critical threshold approximately follows a square root law, suggesting the existence of a supercritical Hopf bifurcation (Fig. 3a). This behavior was first recognized in an idealized ocean model coupled to an energy balance model of the atmosphere by Chen and Ghil (1996) 

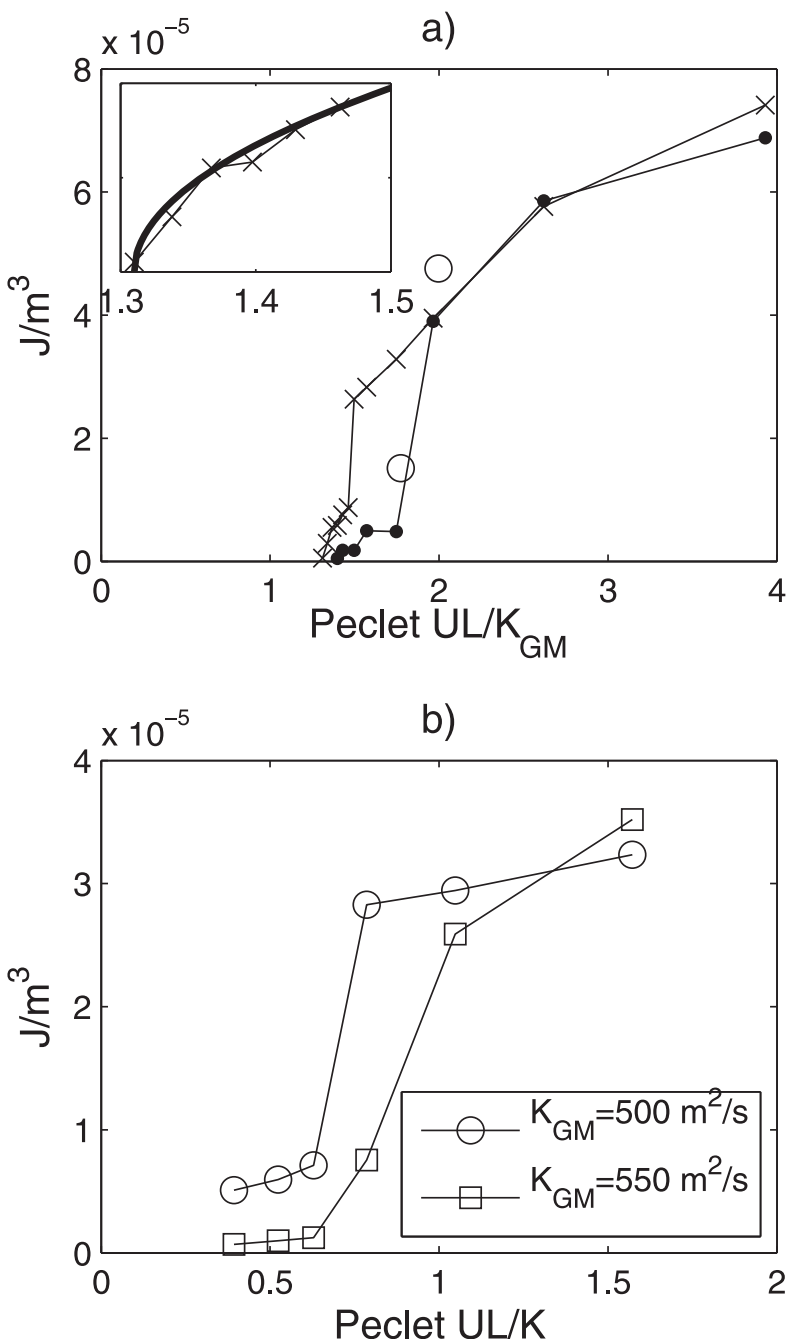

FIG. 3. Amplitude of the circulation variability as a function of the Peclet number (with $U=1 \mathrm{~cm} \mathrm{~s}^{-1}$ and $L=75 \mathrm{~km}$ the grid size at midlatitudes) based on (a) $K_{\mathrm{GM}}$ and (b) $K$. The index is computed as the peak-to-peak variations of the North Atlantic kinetic energy density time series. The inset in (a) emphasizes the presence of a supercritical Hopf bifurcation where the amplitude of the limit cycle in the vicinity of the critical Peclet number $\mathrm{Pe}_{c}=1.31$ increases as $\left(\mathrm{Pe}-\mathrm{Pe}_{c}\right)^{1 / 2}$, as indicated by the thick black line. In (a) the two circles correspond to the case with spatially varying GM coefficients. The associated Peclet numbers have been computed as the average in the region of maximum SST variance. The crosses correspond to the standard experiments under flux boundary conditions, while the black dots correspond to the case where a thermal damping has been added to the prescribed heat flux with a restoring time scale of $1 \mathrm{yr}$.

but with the inverse of the heat exchange coefficient as the control parameter. Colin de Verdière and Huck (1999) later confirmed the nature of the bifurcation in an idealized ocean model forced by prescribed surface buoyancy fluxes with the horizontal Peclet number as the control parameter.
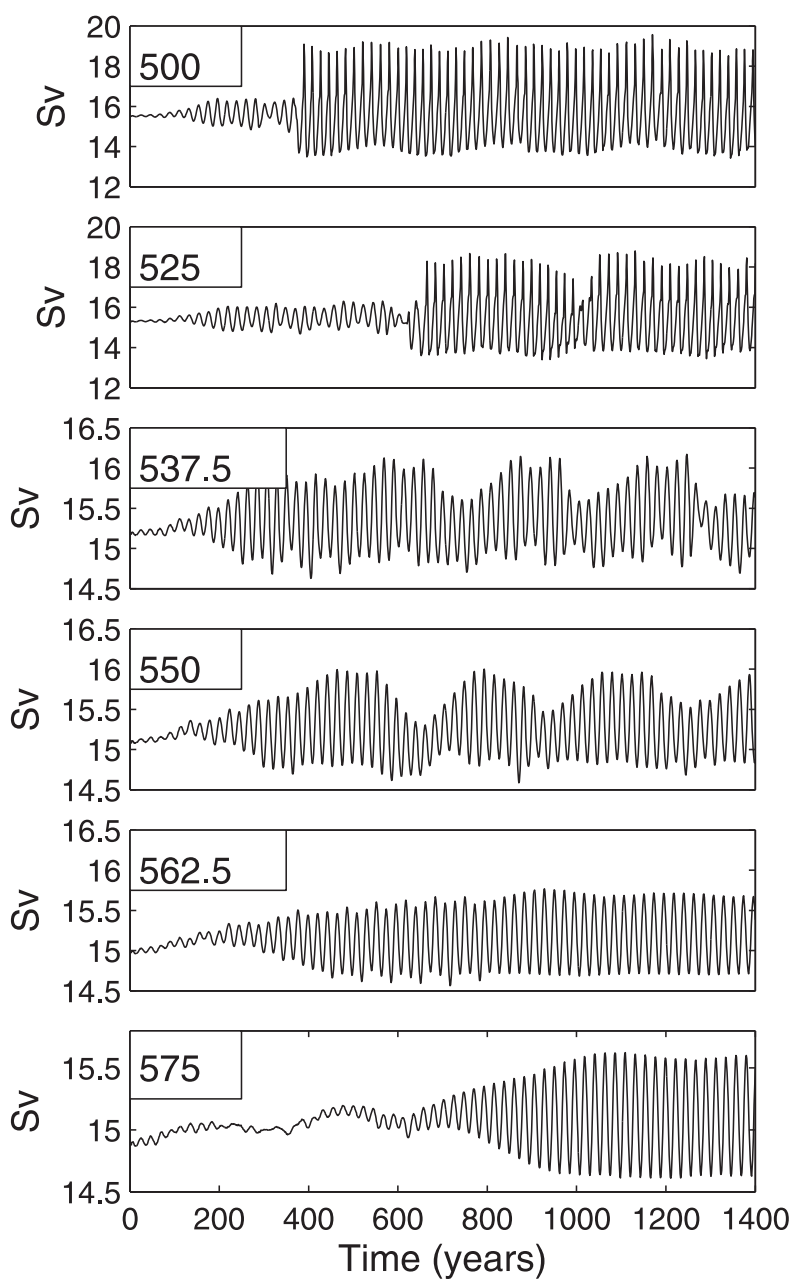

FIG. 4. Time series of the AMOC index obtained under flux boundary conditions for $K_{\mathrm{GM}}$ varying from 500 to $575 \mathrm{~m}^{2} \mathrm{~s}^{-1}$, keeping $K=1000 \mathrm{~m}^{2} \mathrm{~s}^{-1}$ in all experiments. Note the different vertical scales between panels.

A second (abrupt) transition in the oscillation amplitude occurs around $\mathrm{Pe}=1.5$ corresponding to $K_{\mathrm{GM}}=$ $525 \mathrm{~m}^{2} \mathrm{~s}^{-1}$ (Fig. 3a). Trials have been made to rationalize this behavior, such as to compare the mean circulation states obtained from the RTRS runs for GM coefficients apart from this critical value, but no significant changes in the mean flow structure or stratification could be found. This is consistent with the initial evolution of the circulation under flux boundary conditions, which exhibits a relatively small amplitude limit cycle for all experiments (typically during the first few centuries; Fig. 4). The difficulty here is that it is the circulation under flux boundary conditions that undergoes an abrupt shift (i.e., at year 650 for $K_{\mathrm{GM}}=525 \mathrm{~m}^{2} \mathrm{~s}^{-1}$ and at year 400 for $K_{\mathrm{GM}}=500 \mathrm{~m}^{2} \mathrm{~s}^{-1}$; Fig. 4). We suggest that as the GM coefficient is reduced, typically to values smaller than $525 \mathrm{~m}^{2} \mathrm{~s}^{-1}$, the mean path of the North 
Atlantic Current under flux boundary conditions becomes less stable and eventually undergoes at some point an abrupt shift, which may ultimately favor much larger amplitude oscillations.

All experiments based on steady and spatially uniform thickness diffusivities need to be contrasted with those using a variable $K_{\mathrm{GM}}$ (Visbeck et al. 1997). Increasing the maximum possible value of $K_{\mathrm{GM}}$ from 500 to $1000 \mathrm{~m}^{2} \mathrm{~s}^{-1}$ with this formulation tends to slightly weaken the AMOC and decrease the oscillation amplitude. The effect on the oscillation period is, however, significant with a drastic decrease of about $50 \%$ between the two experiments.

\section{b. Sensitivity to isopycnal mixing $K$}

Keeping now $K_{\mathrm{GM}}$ fixed and varying $K$ in the 500$2000 \mathrm{~m}^{2} \mathrm{~s}^{-1}$ range has a negligible effect on the strength of mean circulation but not on the oscillation properties (Figs. 2 and 3). The boundary between the weak and strong variability regimes occurs around $K=1000$ $1200 \mathrm{~m}^{2} \mathrm{~s}^{-1}$. The transition between the two regimes is quite abrupt, in particular for $K_{\mathrm{GM}}=550 \mathrm{~m}^{2} \mathrm{~s}^{-1}$ (Fig. 3b), and may eventually be traced back to the different structure of the mean circulation rather than its strength, which appears to be weakly dependent of $K$ (Fig. 2b). By contrast to the sensitivity to $K_{\mathrm{GM}}$ where a Hopf bifurcation occurs, the amplitude of the limit cycle does not reduce to zero as $K$ increases. The period of oscillations in the strong variability regime $\left[K<O(1000) \mathrm{m}^{2} \mathrm{~s}^{-1}\right]$ is relatively constant, with periods of $O(20)$ yr. We finally note a drastic increase of the period to about $50 \mathrm{yr}$ in the weak variability regime $\left[K>O(1200) \mathrm{m}^{2} \mathrm{~s}^{-1}\right.$ and AMOC standard deviation $O(0.1) \mathrm{Sv}]$ for $K_{\mathrm{GM}}=550 \mathrm{~m}^{2} \mathrm{~s}^{-1}$.

\section{c. The variability in terms of SST-based indices}

The amplitude of the variability in terms of SST is usually estimated by computing the AMO index, which is defined as the detrended low-pass-filtered SST areaweighted average over the North Atlantic $\left(0^{\circ}-70^{\circ} \mathrm{N}\right)$ (Enfield et al. 2001). In the present case, coherent multicentennial variations are found in most of the simulations [see Sévellec et al. (2006) for a mechanistic understanding of intrinsic centennial modes in zonally averaged ocean models]. This long-term variability appears to be driven by North Atlantic SSS changes (not shown), similar to Delworth and Zeng (2012) realistic coupled model simulations. Its amplitude in terms of area-average SST sometimes exceeds its counterpart at the decadal time scale, in particular when approaching the Hopf bifurcation. By contrast to AMOC index spectra, AMO spectra tend to have a much stronger peak at centennial than at decadal time scales. A measure of the amplitude of the decadal variability in terms of SST is thus best obtained by applying a high-pass filter to the AMO index time series, with a cutoff frequency of $1 / 100 \mathrm{yr}^{-1}$, leading to what we define as the AMV index. The correlation between the AMOC and the new AMV index typically increases by a factor of 2-3 compared to that obtained with the standard AMO index, with correlation $r$ reaching $0.7-0.9$ depending on the experiments, significant at the $95 \%$ confidence level. The peak-to-peak amplitude of the AMV index is $0.2^{\circ} \mathrm{C}$ (Figs. 2b,c) for $K_{\mathrm{GM}}<525 \mathrm{~m}^{2} \mathrm{~s}^{-1}$ and $K<1250 \mathrm{~m}^{2} \mathrm{~s}^{-1}$, which is smaller than the observed AMO index $\left[0.3^{\circ}-0.4^{\circ} \mathrm{C}\right.$, depending on the method used to remove the anthropogenic signal (Enfield et al. 2001; Knight 2009)]. This difference is presumably due to SST changes in the tropics that are absent in the model and are thought to be caused by thermal coupling between the ocean and the atmosphere (Xie 1999).

\section{d. The period of the variability}

The time scale of the variability (estimated from a multitaper spectral analysis of the basin mean kinetic energy density time series) near this bifurcation point appears to be nearly constant with a period of about $22 \mathrm{yr}$. This time scale is consistent with that found in the analyses of tide gauge records from around the North Atlantic (Frankcombe and Dijkstra 2009) and from the central England temperature record (Plaut et al. 1995). Similarly, a number of studies based on idealized models (Huck et al. 2001; Arzel et al. 2006, 2007), realistic ocean models (Arzel et al. 2012; Sévellec and Fedorov 2013; Ortega et al. 2015), and coupled models (Timmermann et al. 1998; Cheng et al. 2004; Dai et al. 2005; Dong and Sutton 2005; Danabasoglu 2008; Zhu and Jungclaus 2008) show an intrinsic variability in the 20-30-yr range. The period of the variability decreases down to about $10 \mathrm{yr}$ for the smallest eddy-induced diffusivities used here, typically for $K_{\mathrm{GM}}<300 \mathrm{~m}^{2} \mathrm{~s}^{-1}$. Larger-amplitude oscillations are also associated with shorter periods and stronger circulation.

\section{e. Impact of thermal damping}

Adding thermal damping to the prescribed heat flux (with a time scale of $1 \mathrm{yr}$ ) displaces the domain of existence of oscillations toward slightly higher Peclet numbers, without significantly changing the bifurcation structure (Fig. 3a). The disappearance of the variability for $600<K_{\mathrm{GM}}<550 \mathrm{~m}^{2} \mathrm{~s}^{-1}$ suggests that $e$-folding times of perturbations near the bifurcation under flux boundary conditions is $O(1)$ yr or less, an intuition that will be confirmed in section 5 .

\section{Description of variability}

We describe here the spontaneous oscillations that arise under flux boundary conditions after the model has 
been spun up for thousands of years under restoring boundary conditions. Hot spots of intrinsic variability as measured by the standard deviation of annual mean SST occur at different locations, namely, in a large area centered at about $40^{\circ} \mathrm{S}$ in the southeastern Pacific with enhanced variance between southeastern Australia and New Zealand, in the core of the Leeuwin Current and its western extension off western Australia, in the western part of the North Atlantic Subpolar Gyre, and to a lesser extent in the tropical Pacific (Fig. 5). Intrinsic ocean modes in the southeastern Indian Ocean Basin and in the southeastern Pacific have been studied by Wolfe et al. (2017) and O'Kane et al. (2013), respectively, and we concentrate here on the North Atlantic.

\section{a. Growth of perturbations and bidecadal oscillations}

Figure 4 shows the time series of the AMOC index (computed as the maximum strength of the meridional overturning streamfunction below $1000 \mathrm{~m}$ and north of $30^{\circ} \mathrm{N}$ ) for $K_{\mathrm{GM}}$ varying from 500 to $575 \mathrm{~m}^{2} \mathrm{~s}^{-1}$. In all cases, the oscillations slowly grow around a circulation state that roughly corresponds to that obtained under restoring boundary conditions. This behavior suggests that the variability originates from a linear instability of the mean circulation obtained under restoring boundary conditions, similar to results deduced from idealized model studies (Fig. 1 in Arzel et al. 2006). For $K_{\mathrm{GM}}=$ 500 and $525 \mathrm{~m}^{2} \mathrm{~s}^{-1}$ the small-amplitude oscillations initially experienced by the circulation for several hundred years are followed by an abrupt transition to a new limit cycle with much larger amplitude, as discussed previously. By contrast, the most diffusive model solutions $\left(K_{\mathrm{GM}} \geq 537.5 \mathrm{~m}^{2} \mathrm{~s}^{-1}\right)$ presented here exhibit relatively small-amplitude oscillations with AMOC variations of $O(1) \mathrm{Sv}$ over the entire model integration duration $(1400 \mathrm{yr})$. For $K_{\mathrm{GM}}=537.5$ and $550 \mathrm{~m}^{2} \mathrm{~s}^{-1}$, multicentennial oscillations are clearly visible in the AMOC time series. These long time scales are present in all simulations and best seen in the averaged North Atlantic SST and SSS

The time series in Fig. 4 also indicate that the closer the model state to the bifurcation (near $K_{\mathrm{GM}}=$ $600 \mathrm{~m}^{2} \mathrm{~s}^{-1}$ ), the smaller the growth rate of oscillations and the longer the time needed for the circulation to settle into a statistically steady limit cycle. This behavior can be appreciated by computing the linear growth rate of oscillations over the growing phase of oscillations (Huck et al. 2001). This growing phase is defined as the time period during which the amplitude of oscillations in North Atlantic-averaged kinetic energy density increases with time. This period typically lasts between 200 and $1000 \mathrm{yr}$ at the beginning of each experiment. The exponential growth of oscillations is deduced from

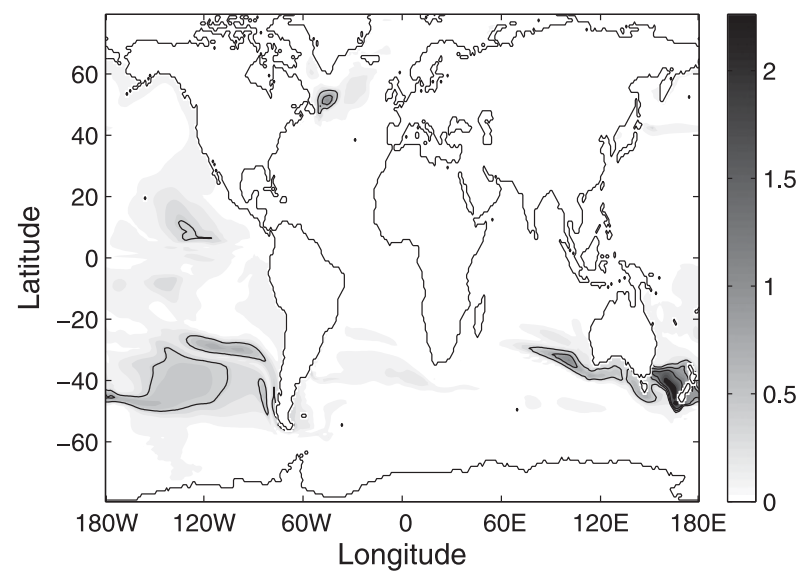

FIG. 5. Standard deviation $\left({ }^{\circ} \mathrm{C}\right)$ of annual mean SST computed over years 1201-1400 for the reference experiment (flux boundary conditions with $K_{\mathrm{GM}}=550 \mathrm{~m}^{2} \mathrm{~s}^{-1}$ and $K=1000 \mathrm{~m}^{2} \mathrm{~s}^{-1}$ ). Contours of $0.5^{\circ}, 1^{\circ}$, and $1.5^{\circ} \mathrm{C}$ are also shown for clarity. No time filtering was applied prior to the analysis. Applying a high-pass filter to remove the multicentennial variability leads to a very similar pattern.

the logarithm of the successive maxima of the North Atlantic-averaged kinetic energy density over this specific time period. This gives exponential growing times in the range of $80-200 \mathrm{yr}$ for $K_{\mathrm{GM}}$ varying from 537.5 to $575 \mathrm{~m}^{2} \mathrm{~s}^{-1}$, which have to be compared to critical damping terms: using a turbulent diffusivity of $1000 \mathrm{~m}^{2} \mathrm{~s}^{-1}$ and a horizontal scale for perturbations of $1000 \mathrm{~km}$, one obtains a damping time scale of about $30 \mathrm{yr}$. The similarity of the growing and diffusive time scales indicates that the model solutions that are being analyzed $\left(537.5<K_{\mathrm{GM}}<575 \mathrm{~m}^{2} \mathrm{~s}^{-1}\right)$ are close to the bifurcation and that the existence of intrinsic oceanic variability under prescribed surface fluxes critically depends on lateral diffusion of tracer variance, in agreement with earlier idealized model studies. It should be noted that these exponential growing times are proportional to the oscillation period, and are therefore intrinsically very different from the $e$-folding times of perturbations that are on the order of $1 \mathrm{yr}$ (section 5).

The amplitude of the decadal variations of the AMOC near the bifurcation $\left(K_{\mathrm{GM}}>525 \mathrm{~m}^{2} \mathrm{~s}^{-1}\right)$ is relatively small, with peak-to-peak amplitude of $O(1) \mathrm{Sv}$, which is sufficient to generate decadal SST anomalies on the order of $1^{\circ} \mathrm{C}$ in the western part of the North Atlantic Subpolar Gyre (Fig. 5). Associated sea surface height (SSH) anomalies are on the order of $10 \mathrm{~cm}$ (not shown), consistent with the magnitude of observed SSH changes during the past 20 years in the subpolar gyre (Häkkinen et al. 2013). This region of maximum variability holds for circulation states far from the bifurcation. However, for $K_{\mathrm{GM}}<525 \mathrm{~m}^{2} \mathrm{~s}^{-1}$, peak-to-peak AMOC fluctuations can reach $4-9 \mathrm{~Sv}$. 
a)

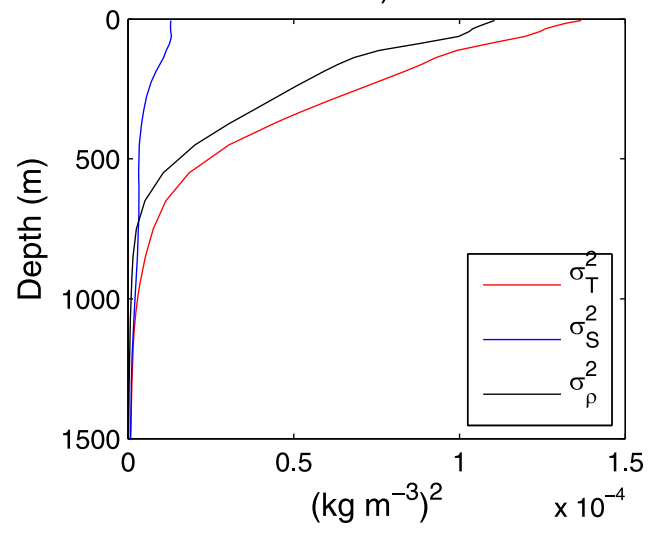

b) Turner angle $\theta$

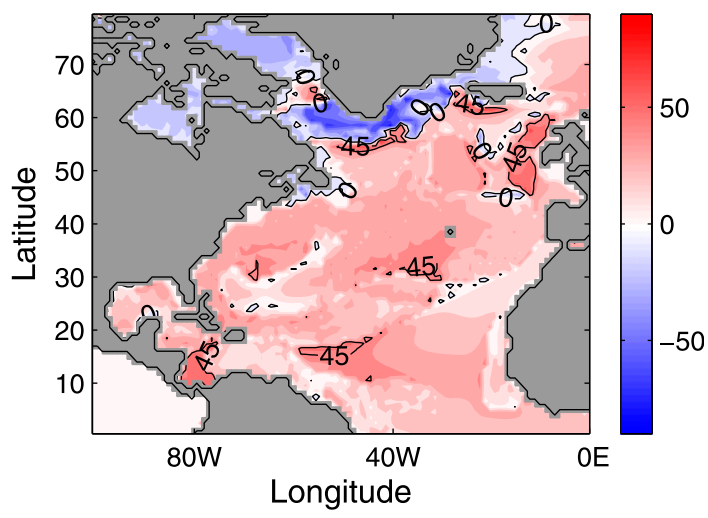

FIG. 6. (a) Horizontally averaged temperature $\sigma_{T}^{2}$, salinity $\sigma_{S}^{2}$, and density $\sigma_{\rho}^{2}$ variance expressed in $\left(\mathrm{kg} \mathrm{m}^{-3}\right)^{2}$ as a function of depth over the North Atlantic. The calculation is based on years 1201-1400 of the reference experiment $\left(K_{\mathrm{GM}}=550 \mathrm{~m}^{2} \mathrm{~s}^{-1}\right.$ and $\left.K=1000 \mathrm{~m}^{2} \mathrm{~s}^{-1}\right)$ and uses, for each model year, the local values of $\alpha_{T}$ and $\beta_{S}$ coefficients (McDougall and Barker 2011). (b) Turner angle (defined in the text) averaged in the upper $500 \mathrm{~m}$ of the North Atlantic. Positive angles smaller than $45^{\circ}$ indicate that density anomalies are controlled by temperature changes whereas salinity changes act to damp density anomalies.

\section{b. The relative role of temperature and salinity}

To determine the relative role of temperature and salinity in density perturbations, we first compute the horizontally averaged tracer and density variances as a function of depth (Fig. 6a). Consistent with the interdecadal variability found in many models, the temperature contribution dominates. To obtain information at the regional scale of the relative roles that the temperature and salinity have, we further compute the Turner angle (Muir and Fedorov 2017), defined as

$$
\tan \theta=\frac{\alpha_{T} \Theta^{\prime}-\beta_{S} S^{\prime}}{\alpha_{T} \Theta^{\prime}+\beta_{S} S^{\prime}},
$$

where the thermal expansion $\alpha_{T}$ and haline contraction $\beta_{S}$ coefficients are calculated using the local values of the time mean temperature and salinity fields (McDougall and Barker 2011). The potential temperature $\Theta^{\prime}$ and salinity $S^{\prime}$ anomalies have been obtained from a regression of the corresponding tracer fields onto the time series of the AMOC index. Positive angles indicate a control of density perturbations (assumed to be linear in the form $\left.-\alpha_{T} \Theta^{\prime}+\beta_{S} S^{\prime}\right)$ by the temperature anomalies. In the area of strongest variability (Fig. 5) most angles are positive and smaller than $45^{\circ}$ (Fig. 6b), indicating that salinity provides a slight compensation on density perturbations similar to what is seen in coupled general circulation models (Muir and Fedorov 2017). By contrast, in the Labrador Sea, Baffin Bay, and Hudson Bay, the Turner angle is negative, indicating that salinity dominates in the density perturbation. However, the density fluctuations there are much smaller than in the interior and do not explain the bulk of the variability. Because decadal circulation anomalies are primarily caused by temperature fluctuations, the description that follows is made in terms of temperature only.

\section{c. The spatial pattern of the variability}

The dominant patterns of variability are determined here by performing an empirical orthogonal function (EOF) analysis of detrended annual mean SST over the North Atlantic region (from the equator to $80^{\circ} \mathrm{N}$ ) and over years 1201-1400 of the reference experiment (Table 1). The dominant pattern of SST variability, explaining $67.3 \%$ of the spatially integrated variance, is characterized by a strong anomaly in the western subpolar gyre region and weaker anomaly of opposite sign in the east (Fig. 7a). The AMOC anomaly associated with this temperature pattern is characterized by a thermally direct circulation (Fig. 7c). The second EOF, which evolves in quadrature with the first one, explains $26.3 \%$ of the spatially integrated variance, so that most of the variability $(93.6 \%)$ is captured by the first two EOFs. The amplitude of SST anomalies corresponding to the second EOF is weaker than those associated with the first one (Fig. 7b). The pattern is characterized by a large-scale anomaly extending throughout most of the subpolar gyre, and a smaller-scale anomaly of opposite sign in the Newfoundland Basin. The AMOC anomaly associated with this second EOF features a thermally indirect circulation in the upper $2500 \mathrm{~m}$ (south of $55^{\circ} \mathrm{N}$ ) and a circulation of opposite sign below. At about $60^{\circ} \mathrm{N}$, a positive streamfunction anomaly extends from the surface to the bottom, which might be related to stronger deep water formation resulting from colder than usual 
a) $\operatorname{reg}(\mathrm{SST}, \mathrm{PC} 1)$

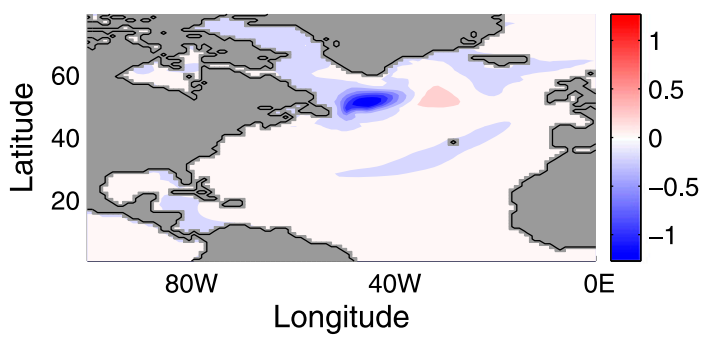

c) $\operatorname{reg}(\mathrm{AMOC}, \mathrm{PC} 1)$

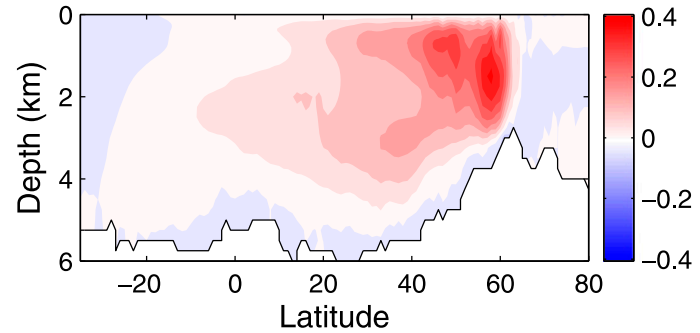

b) reg(SST,PC2)

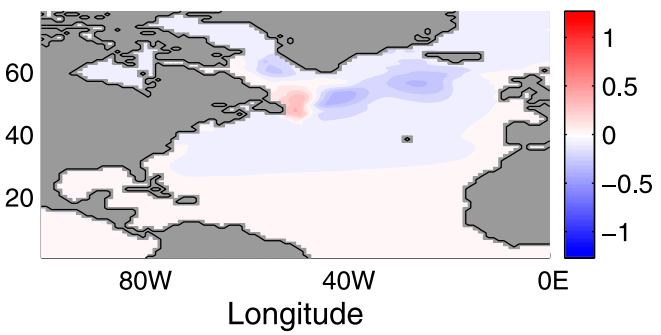

d) $\operatorname{reg}(\mathrm{AMOC}, \mathrm{PC} 2)$

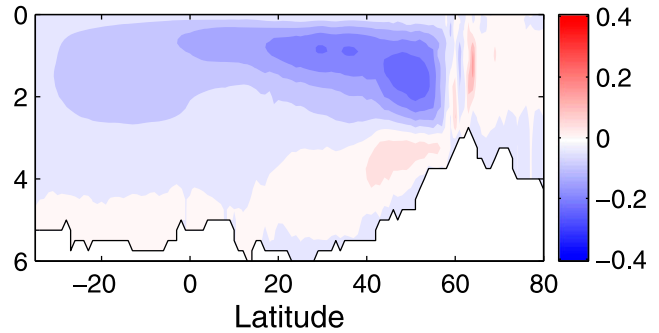

e) timeseries of the first two EOFs of annual mean SST

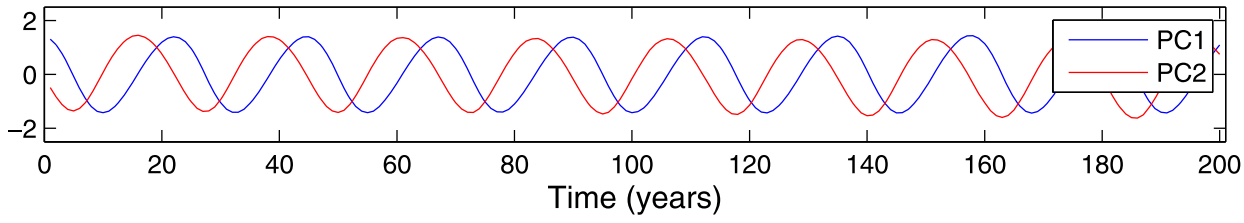

FIG. 7. Dominant patterns of variability deduced from an EOF analysis of annual mean SST over years 1201-1400 of the reference experiment $\left(K_{\mathrm{GM}}=550 \mathrm{~m}^{2} \mathrm{~s}^{-1}\right.$ and $\left.K=1000 \mathrm{~m}^{2} \mathrm{~s}^{-1}\right)$. Linear regressions of annual mean (a), (b) SST and (c),(d) overturning streamfunction onto the time series of the (a),(c) first and (b),(d) second EOF of annual mean SST multiplied by one standard deviation of these time series. The patterns thereby indicate SST $\left({ }^{\circ} \mathrm{C}\right)$ and AMOC (Sv) anomalies associated with one standard deviation of the corresponding EOF. (e) The first two principal components of annual mean SST. The first (second) EOF explains $63.7 \%(25.5 \%)$ of the spatially integrated variance.

conditions at the surface in the Labrador Sea (Fig. 7b). The EOF time series shown in Fig. 7c indicate that the second EOF leads the first one by $5 \mathrm{yr}$, which corresponds to a fourth of an oscillation cycle. From this analysis we anticipate that the relatively weak SST anomaly present around $40^{\circ} \mathrm{W}$, just south of the southern tip of Greenland in Fig. $7 \mathrm{~b}$, is amplified when propagating westward and reaches a maximum in the western part of the subpolar gyre five years later (Fig. 7a).

This analysis has been repeated for all experiments. No significant differences from what is presented in Fig. 7 was noticed for most experiments except that the fraction of the first two EOFs explaining the total integrated variance decreases with decreasing values of $K_{\mathrm{GM}}$ (until $43.4 \%$ for $K_{\mathrm{GM}}=200 \mathrm{~m}^{2} \mathrm{~s}^{-1}$ ).

\section{d. Propagation of surface-intensified temperature signals}

Westward propagation of temperature anomalies in the first $1000 \mathrm{~m}$ or so are ubiquitous in idealized models
(Chen and Ghil 1996; te Raa and Dijkstra 2002; Colin de Verdière and Huck 1999). This propagation has been attributed to long unstable baroclinic planetary waves. The zonal phase speed is generally difficult to rationalize because of the strong wave-mean flow interaction. In realistic coupled models, however, westward propagation is not the rule and a number of models exhibit eastward propagation instead (Muir and Fedorov 2017). These differences do not however necessarily imply that different mechanisms are at play: the source of the variability may well be the same and it may be simply the expression of the variability that differs. The latter point is intimately related to the mean flow structure that influences the propagation direction. In the present case, the characteristic phase diagram of SST anomalies in the longitude-time $(x-t)$ plane (Fig. 8 ) shows a partition between the region west of the North Atlantic Current (centered at about $40^{\circ} \mathrm{W}$ at $50^{\circ} \mathrm{N}$ ) where the temperature anomalies are large and propagate westward, and the region east of that position where the temperature anomalies are weak 


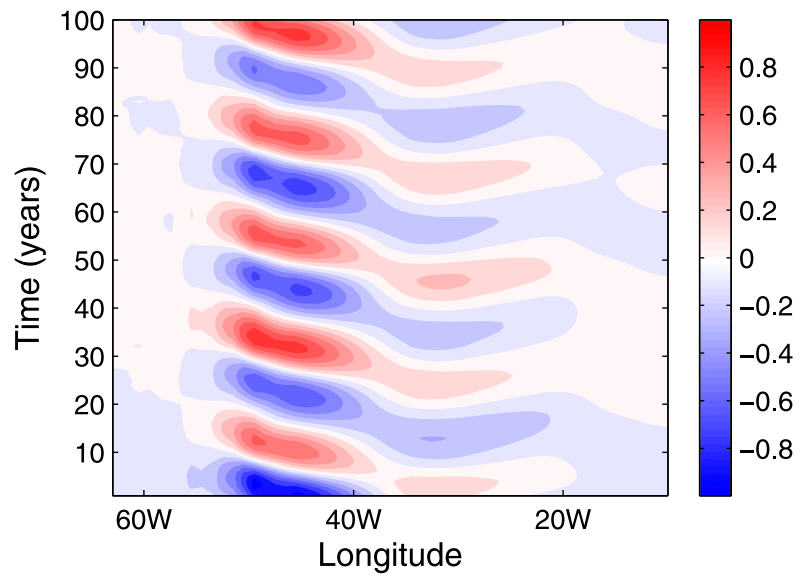

FIG. 8. Longitude-time phase diagram of (detrendred) SST anomalies averaged between $45^{\circ}$ and $55^{\circ} \mathrm{N}$ over years $1201-1300$ of the reference experiment $\left(K_{\mathrm{GM}}=550 \mathrm{~m}^{2} \mathrm{~s}^{-1}\right.$ and $\left.K=1000 \mathrm{~m}^{2} \mathrm{~s}^{-1}\right)$. West of $40^{\circ} \mathrm{W}$, the average position of the NAC at $50^{\circ} \mathrm{N}$, westward propagation of relatively large SST anomalies stands out. East of that area, weaker SST anomalies propagate eastward.

and propagate eastward. This pattern of propagation can also be inferred from the evolution of SST anomalies during an oscillation cycle in Fig. 9.

The western anomalies take about 10 years (half an oscillation period) to travel from the western flank of the North Atlantic Current (NAC) to the western boundary, a time scale broadly consistent with the transit time of the first baroclinic Rossby mode, given by
$L /\left(\beta R_{i}^{2}\right)$, where $L=800 \mathrm{~km}$ is the distance traveled by the waves between the source region and the western boundary (from $40^{\circ}$ to $50^{\circ} \mathrm{W}$ at $50^{\circ} \mathrm{N}$ ), $\beta=1.5 \times$ $10^{-11} \mathrm{~m}^{-1} \mathrm{~s}^{-1}$ is the planetary vorticity gradient, and $R_{i}=12 \mathrm{~km}$ is the internal Rossby radius averaged in the region (estimated by solving the Sturm-Liouville eigenvalue problem for the stratification modes at the gridpoint level in the region of interest). With these values we obtain a transit time on the order of $10 \mathrm{yr}$, or half a period of the model oscillations.

\section{e. Energy source}

Positive meridional eddy fluxes of buoyancy $\overline{v^{\prime} b^{\prime}}$ (where the overbar denotes a time average, the prime denotes the difference therefrom from now on, and $\left.b=-g \rho / \rho_{0}\right)$ along the western boundary have been shown to be at the heart of the existence of oscillations under flux boundary conditions in idealized boxgeometry ocean models (Colin de Verdière and Huck 1999). When these fluxes are oriented down the mean buoyancy gradient, potential energy of the mean flow is converted to potential energy of perturbations through the term $-\overline{\mathbf{u}^{\prime} b^{\prime}} \cdot \nabla \bar{b}$. Under flux boundary conditions, this term is the only one able to create tracer variance globally \{The advection of tracer variance by the mean flow redistributes the variance horizontally while the diffusion term damps the signal. For the small-amplitude perturbations considered here, the advection of tracer variance by the perturbation velocities can be neglected

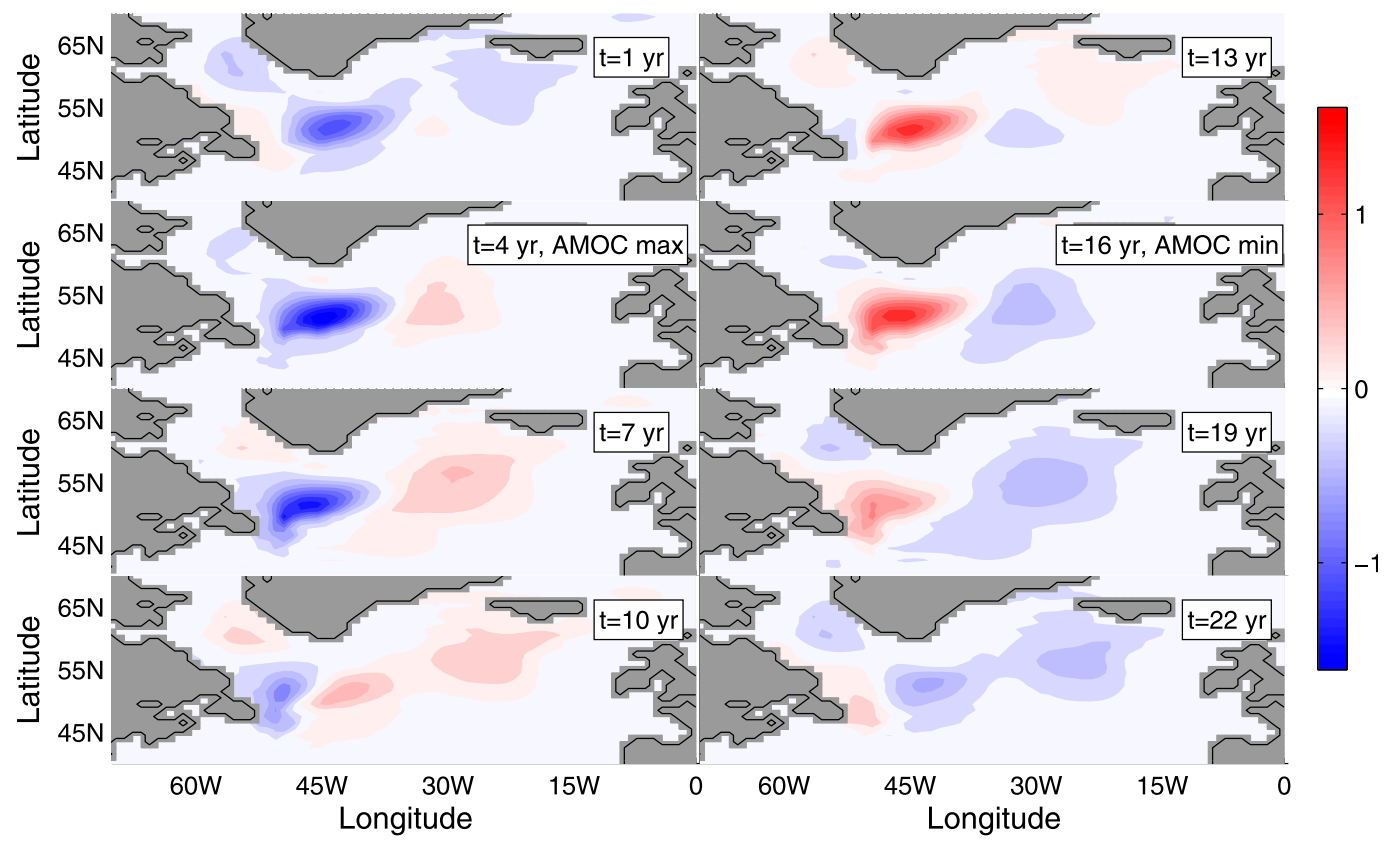

FIG. 9. Evolution of SST anomalies $\left({ }^{\circ} \mathrm{C}\right)$ during an oscillation cycle for the reference experiment $\left(K_{\mathrm{GM}}=550 \mathrm{~m}^{2} \mathrm{~s}^{-1}\right.$ and $K=1000 \mathrm{~m}^{2} \mathrm{~s}^{-1}$ ). 

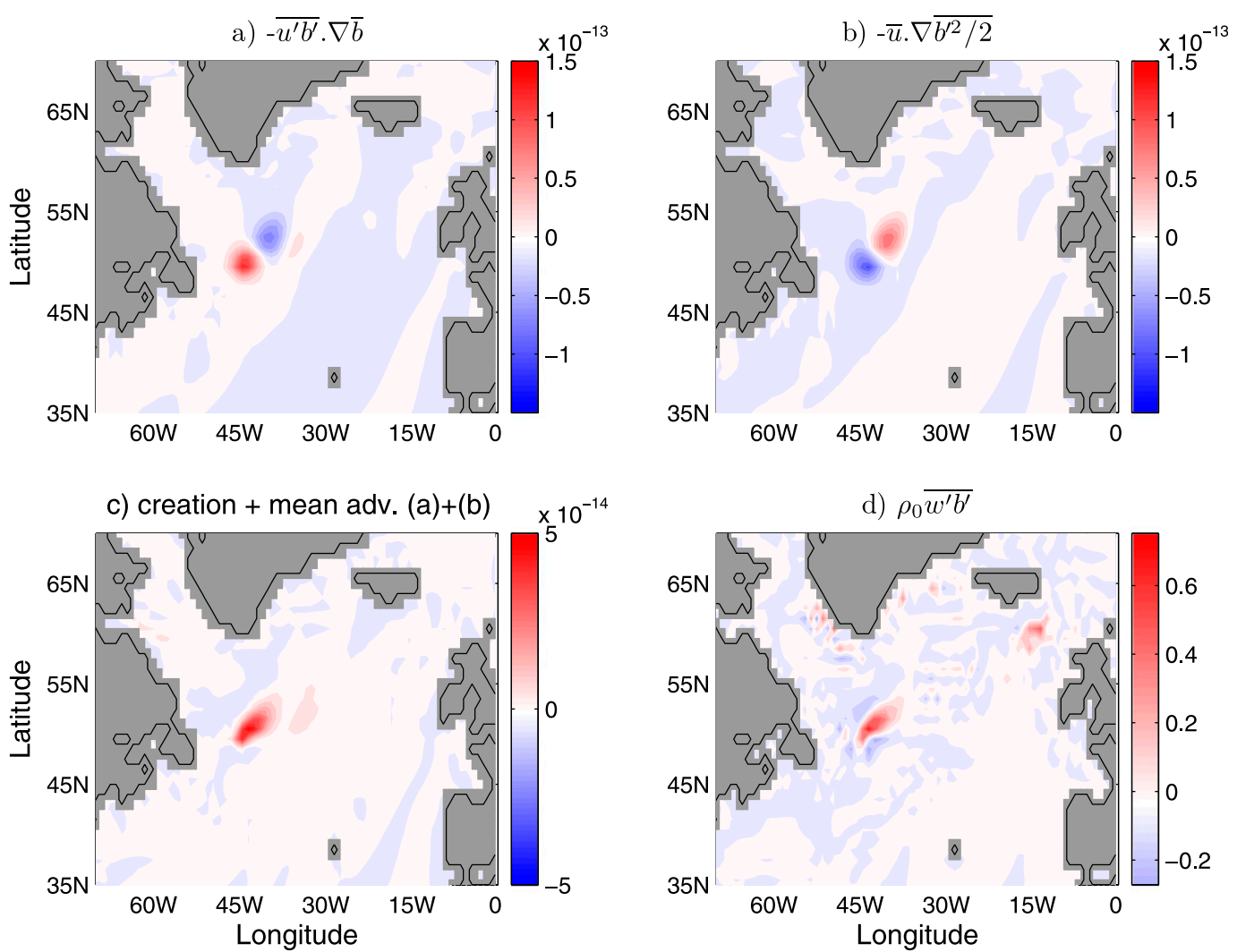

FIG. 10. Terms responsible for the growth of buoyancy variance and eddy kinetic energy. (a) Vertically averaged

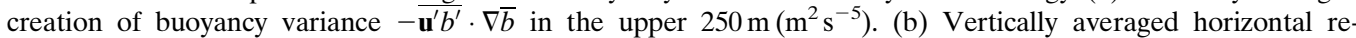

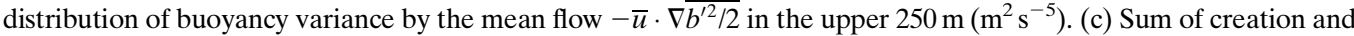
horizontal redistribution of buoyancy variance $[(a)+(b)]$. (d) Vertically integrated baroclinic energy conversion rate $\rho_{0} \overline{w^{\prime} b^{\prime}}\left(\mathrm{mW} \mathrm{m}^{-2}\right)$ in the upper $1000 \mathrm{~m}$.

[see Arzel et al. (2006) for a detailed analysis of the tracer variance equation]\}. Note that our calculation is based on Eulerian velocities, excluding the eddy transport velocity associated with the GM parameterization. Therefore, positive values of $-\overline{\mathbf{u}^{\prime} b^{\prime}} \cdot \nabla \bar{b}$ are attributed to the resolved (large scale) baroclinic instability of the Eulerian mean flow and not to the GM scheme. The spatial distribution of $-\overline{\mathbf{u}^{\prime} b^{\prime}} \cdot \nabla \bar{b}$ (Fig. 10a) shows a positive contribution around $40^{\circ} \mathrm{W}-50^{\circ} \mathrm{N}$ where the mean flow has a strong northward component. These positive values indicate a growth of perturbations, while the negative ones seen farther downstream of the North Atlantic Current indicate a decay of perturbations. Such a dipole structure in the western boundary current and its eastward extension was also found in idealized stand-alone and coupled model studies (Colin de Verdière and Huck 1999; Arzel et al. 2006, 2007). Buckley et al. (2012) and Jamet et al. (2016) also reported on the creation of buoyancy variance through the term $-\overline{\mathbf{u}^{\prime} T^{\prime}} \cdot \nabla \bar{T}$ along both the western and eastern boundaries of the subpolar gyre in idealized coupled simulations. This pattern is partly compensated by the mean advection of buoyancy variance (Fig. 10b), resulting in a small, but positive, contribution (Fig. 10c). The spatial distribution of the vertically integrated baroclinic conversion rate $\rho_{0} \overline{w^{\prime} b^{\prime}}$ further indicates that perturbations are drawing their energy from the potential energy of the mean circulation. The site of conversion is collocated with the region of growth of perturbations.

\section{f. Vertical structure of perturbations}

In what follows we focus on the situation at $52^{\circ} \mathrm{N}$, which corresponds to the latitude where westward propagation is the most apparent and instability of the mean flow is thought to occur. On the western flank of the NAC, the temperature and the meridional flow correlate positively (Fig. 11a). The meridional flow is to a high degree geostrophic at the (coarse) horizontal resolution used here so that the pressure field must reach an extrema east of the temperature extrema coinciding with $\overline{v^{\prime} T^{\prime}}>0$. As a result, temperature anomalies must necessarily be tilted in the vertical to satisfy hydrostatic balance. A characteristic diagram of temperature anomalies in the depth-time $(z-t)$ 
a) eddy $T$ fluxes

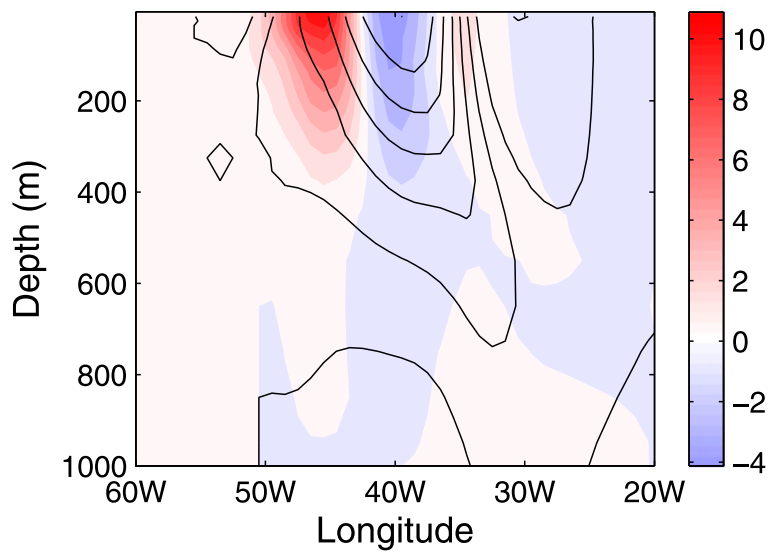

b) z-t diagram of $T$ anomalies

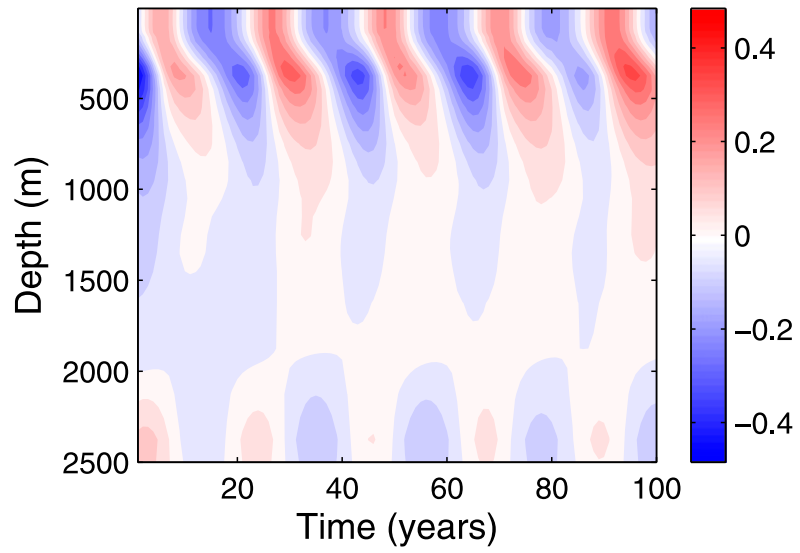

FIG. 11. (a) Eddy temperature fluxes $\overline{v^{\prime} T^{\prime}}$ (color shading; values must be multiplied by $10^{-3}$ to obtain the units $\mathrm{K} \mathrm{m} \mathrm{s}^{-1}$ ) superimposed on contours (black) of mean meridional velocity (solid contours indicate northward flow; contours spaced by $1 \mathrm{~cm} \mathrm{~s}^{-1}$ ) at $52^{\circ} \mathrm{N}$. (b) Characteristic diagram of temperature anomalies (K) in the $z-t$ plane. These temperature anomalies have been averaged horizontally at each depth between $40^{\circ}$ and $35^{\circ} \mathrm{W}$ at $52^{\circ} \mathrm{N}$.

plane east of the region characterized by positive eddy temperature fluxes shows that temperature anomalies are indeed strongly phase-lagged on the vertical (Fig. 11b). The phase lag is about one-quarter period, with the surface anomalies leading the deeper ones, similar to the typical organization of unstable baroclinic Rossby waves evolving in a zonal shear flow under quasigeostrophic dynamics (Pedlosky 1987). This picture strongly suggests that the basic mechanism driving the interdecadal variability is a large-scale baroclinic instability of the North Atlantic Current. The instability has been termed "large scale" because at the coarse resolution used here the physics that develop at the Rossby radius have been left behind, making the evolution of the perturbations frictionally dependent (Colin de Verdière 1986). We will come back to this point later on.

\section{g. Potential vorticity structure}

To gain further insight into the mechanism responsible for the variability, we examine here the mean potential vorticity structure in the North Atlantic. The mean state is diagnosed from the RTRS reference experiment with $K_{\mathrm{GM}}=550 \mathrm{~m}^{2} \mathrm{~s}^{-1}$ and $K=1000 \mathrm{~m}^{2} \mathrm{~s}^{-1}$. Note that this state is nearly identical to that computed from the FTFS run since perturbations basically grow and evolve around the equilibrated state obtained at the end of the spinup phase (Fig. 4). We compute the large-scale potential vorticity (PV) $Q=f N^{2}$, where $f$ is the Coriolis parameter, and $N^{2}$ is the buoyancy frequency. A necessary condition for baroclinic instability is that the meridional gradient $Q_{y}$ changes sign in the domain (Pedlosky 1987). We examine the possibility that this occurs in the subpolar gyre between $40^{\circ}$ and $35^{\circ} \mathrm{W}$, that is, within the longitude band where temperature anomalies are one-quarter phaselagged on the vertical. The zonal section of $Q_{y}$ at our working latitude of $52^{\circ} \mathrm{N}$ confirms this expectation (Fig. 12a). The northward decrease of $Q$ between the northern part of the subsurface subtropical ocean and the subpolar gyre is clearly apparent between $40^{\circ}$ and $35^{\circ} \mathrm{W}$ at $52^{\circ} \mathrm{N}$ and $200-\mathrm{m}$ depth (Fig. 12b). No reverse in the sign of $Q_{y}$ occurs at other locations at this specific latitude. Such a vertical structure $\left(Q_{y}>0\right.$ in the upper ocean and $Q_{y}<0$ below) is associated with westerly sheared flows, as discussed by Tulloch et al. (2011). The depth of the sign reversal in $Q_{y}$ is also consistent with the vertical structure of perturbations that are strongly tilted at about 200-m depth (Fig. 11b). Although the condition that $Q_{y}$ changes sign in the domain is only a necessary condition for instability, this brief analysis gives further support to the idea that the interdecadal variability in the model is driven by a baroclinic instability of the North Atlantic Current at subpolar latitudes.

\section{Local linear stability analysis}

The nonlinear model integrations described previously show that the subpolar circulation is spontaneously unstable on decadal time scales with horizontal scales much larger than the first deformation radius. Other regions in the North Atlantic remain remarkably quiescent (see also Sévellec and Fedorov 2013). In this section, we show that the region of maximum variance east of Newfoundland in our simulations can be predicted by a local linear stability analysis of the mean flow, similar to that of Smith (2007) at the eddy scale and Hochet et al. (2015) at the longwave limit. The local approximation represents of course a strong simplification to the full problem as emphasized by Tulloch et al. (2011). The approximation assumes in particular that at 

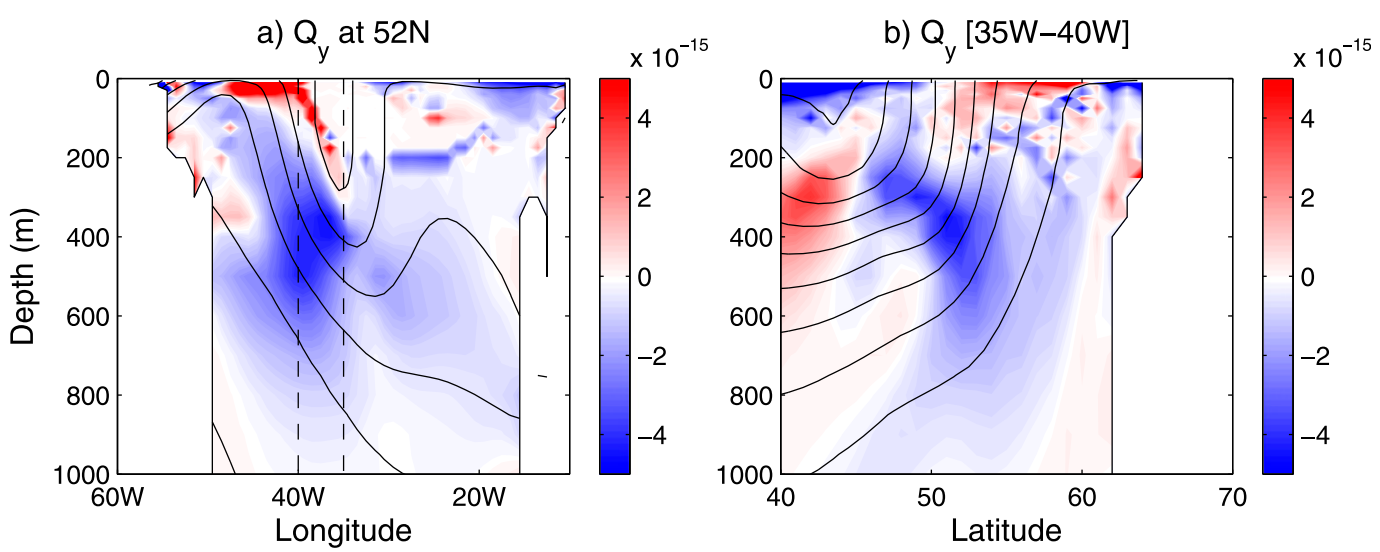

FIG. 12. Meridional gradient of large-scale PV $Q_{y}\left(\mathrm{~m}^{-1} \mathrm{~s}^{-3}\right)$ along a zonal cross section at (a) $52^{\circ} \mathrm{N}$ and (b) zonally averaged between $40^{\circ}$ and $35^{\circ} \mathrm{W}$ in the North Atlantic. The dashed lines in (a) delineate the $40^{\circ}-35^{\circ} \mathrm{W}$ area where the temperature anomalies are strongly tilted on the vertical (see Fig. 11b). Potential density contours (black solid, contour interval of $0.2 \mathrm{~kg} \mathrm{~m}^{-3}$ ) are superimposed.

each location ocean properties are horizontally uniform. This is obviously not the case near continental margins such as western boundary currents for instance. Therefore, unstable modes emerging near continental boundaries will not be considered wherever their horizontal scale is larger than the distance separating them from the coast.

In the present case, we focus our attention on the unstable modes developing around the background state obtained in the reference RTRS experiment with $K_{\mathrm{GM}}=550 \mathrm{~m}^{2} \mathrm{~s}^{-1}$ and $K=1000 \mathrm{~m}^{2} \mathrm{~s}^{-1}$. Within this framework, perturbed velocities are at least an order of magnitude smaller than the mean flow (not shown), consistent with the result that this state lies at proximity of the (Hopf) bifurcation. The linear approximation used in the local stability analysis is therefore expected to be well suited to this specific experiment.

We use the quasigeostrophic (QG) scaling and restrict our attention to unstable modes with horizontal scales larger than $500 \mathrm{~km}$ to filter out instability at the mesoscale that is absent in our simulations. The QG scaling assumes that background velocities are horizontally nondivergent. This is not the case of surface Ekman flow. In addition, Ekman velocities near the surface generate very strong vertical shears leading to instabilities at scales much smaller than the first deformation radius, which are irrelevant for both the QG scaling and the present scales of interest. The Ekman flow will thus be discarded and the surface velocities are computed from geostrophy using annual mean SSH. The results from the local linear stability analysis are identical when the ageostrophic part is computed from the annual mean surface wind stress and is removed from the total surface flow (not shown).
The comparison of the local linear theory with numerical simulations is meaningful when effects such as viscosity and turbulent eddy diffusivity are included in the calculation. Baroclinic growth rates are computed by solving the linearized quasigeostrophic equations about the background streamfunction $\Psi=V(z) x-U(z) y$ and stratification $N^{2}(z)$, in the presence of both horizontal and vertical vis$\operatorname{cosity}\left(\nu_{h}\right.$ and $\nu_{v}$, respectively) and turbulent diffusivity ( $k_{h}$ and $k_{v}$, respectively):

$$
\begin{gathered}
\partial_{t} q+J(\Psi, q)+J(\psi, \beta y+\Gamma \Psi)=\nu_{h} \nabla^{4} \psi+\nu_{v} \nabla^{2} \psi_{z z} \\
+k_{h} \nabla^{2} \Gamma \psi+\Gamma\left(k_{v} \psi_{z z}\right) \text { for }-H<z<0 \text { and } \\
\partial_{t} b+J(\Psi, b)+J\left(\psi, f \partial_{z} \Psi\right)=k_{h} \nabla^{2} b \\
+\partial_{z}\left(k_{v} \partial_{z} b\right) \text { for } z=-H, 0
\end{gathered}
$$

where $J$ is the Jacobian operator, $\Gamma=\partial_{z}\left(f^{2} / N^{2} \partial_{z}\right)$ is the vortex stretching operator, $b=f \partial_{z} \psi$ is the buoyancy, and $q=\nabla^{2} \psi+\Gamma \psi$ is the quasigeostrophic potential vorticity. Mixing coefficients used in the linear stability analysis are identical to those used in the nonlinear model integrations. The vertical mixing coefficient combines the contribution from small-scale turbulent mixing, which obeys a Bryan-Lewis vertical distribution, and convective mixing (see section 2 ). Boundary conditions assume a rigid lid at the surface and a flat bottom with zero normal flow. Plane wave solutions of the form $\psi=\boldsymbol{\phi}(z) \exp [i(\mathbf{K} \cdot \mathbf{x}-\omega t)]$ are introduced in (2), where $\mathbf{K}=K(\cos \alpha \mathbf{i}+\sin \alpha \mathbf{j})$ is the wavenumber vector, $\omega=\omega_{r}+i \omega_{i}$ is the eigenvalue, and $\boldsymbol{\phi}(z)$ is the 
a) adiabatic

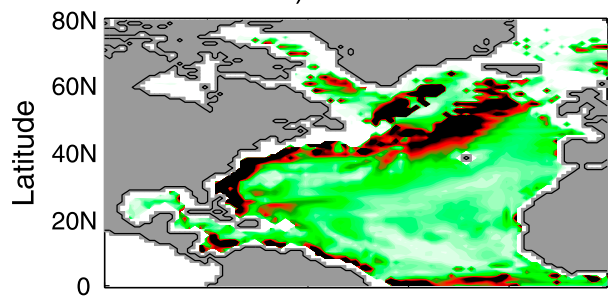

c) viscous (horiz.+vert.)

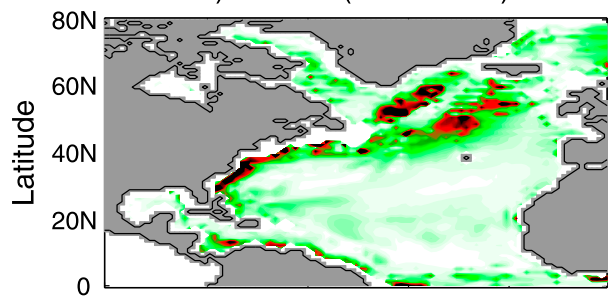

e) viscous+diff.

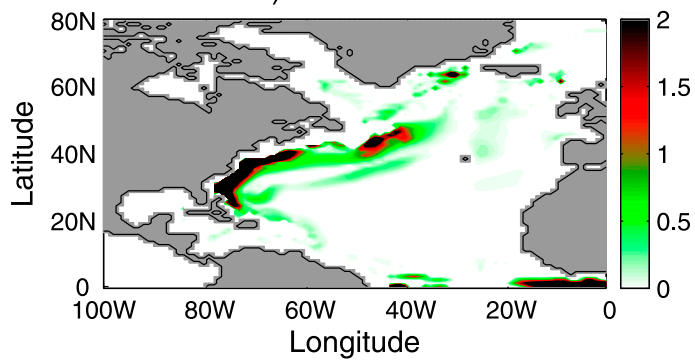

b) viscous (horiz)

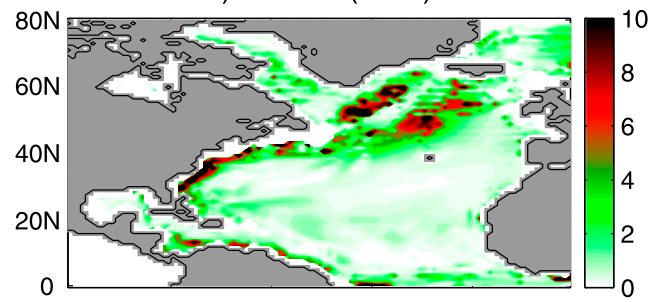

d) viscous+horiz.diff.

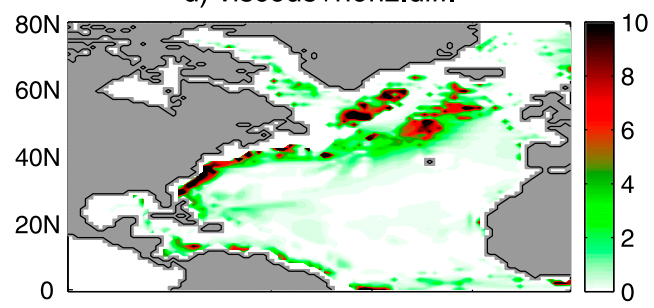

f) viscous+diff.+conv.

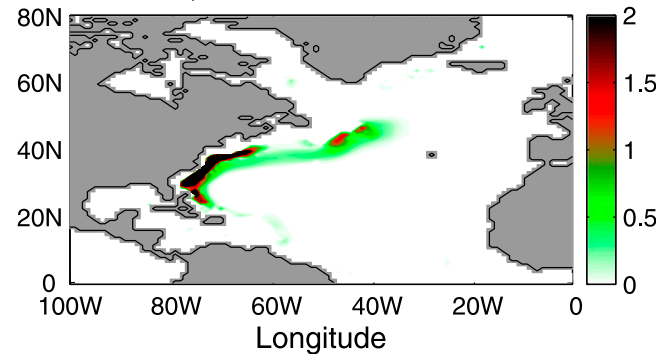

FIG. 13. Results of the linear stability analysis performed around the mean oceanic state obtained in the reference RTRS experiment with $K_{\mathrm{GM}}=550 \mathrm{~m}^{2} \mathrm{~s}^{-1}$ and $K=1000 \mathrm{~m}^{2} \mathrm{~s}^{-1}$. Only unstable vertical modes with horizontal scales larger than $500 \mathrm{~km}$ are considered. [Eddy viscosity and turbulent diffusivity are progressively added in the standard analysis when moving from (a) to (f).] Shown are the spatial distributions of growth rates $\omega_{i}\left(\mathrm{yr}^{-1}\right)$ under various conditions: (a) adiabatic, (b) viscous with $\nu_{h}=5 \times 10^{4} \mathrm{~m}^{2} \mathrm{~s}^{-1}$, (c) as in (b), but $\nu_{v}=10^{-4} \mathrm{~m}^{2} \mathrm{~s}^{-1}$ is added (same value as in the model), (d) as in (c), but with $k_{h}=500 \mathrm{~m}^{2} \mathrm{~s}^{-1},(\mathrm{e})$ as in (d), but with a $k_{v}$ following a BryanLewis vertical profile (as in the model), and (f) as in (e), but with convective mixing acting in the March mixed layer diagnosed from the reference RTRS run. Note the different color scales in (e) and (f).

eigenvector. With these definitions, the generalized eigenvalue problem to be solved becomes

$$
\begin{aligned}
\omega \Gamma \boldsymbol{\phi}= & \left(\mathbf{K} \cdot \mathbf{U}-i k_{h} K^{2}\right) \Gamma \boldsymbol{\phi}+K[(\beta-\Gamma U) \cos \alpha \\
& \left.-\Gamma V \sin \alpha+i \nu_{h} K^{3}\right] \boldsymbol{\phi}+i \Gamma\left(k_{v} \boldsymbol{\phi}_{z z}\right) \\
& -i \nu_{v} K^{2} \boldsymbol{\phi}_{z z} \text { for }-H<z<0 \text { and } \\
\omega \boldsymbol{\phi}_{z}= & \left(\mathbf{K} \cdot \mathbf{U}-i k_{h} K^{2}\right) \boldsymbol{\phi}_{z}-K\left(U_{z} \cos \alpha+V_{z} \sin \alpha\right) \boldsymbol{\phi} \\
& +i\left(k_{v} \boldsymbol{\phi}_{z z}\right)_{z} \text { for } z=-H, 0 .
\end{aligned}
$$

The problem is discretized on the 44-model layers following the method of Tulloch et al. (2009). The eigenvalue problem is solved at each grid point in the North Atlantic for $\alpha$ varying from 0 to $2 \pi$ and for $K$ varying from 0 to $2 \pi / 500 \mathrm{~km}^{-1}$. At each location, the largest growth rate is obtained by selecting the maximum value of $\omega_{i}$ in the $(K, \alpha)$ plane, and its distribution across the North Atlantic is presented in Fig. 13. In the adiabatic limit (Fig. 13a), the largest growths are found over most of the subpolar gyre, along the western boundary current, and near the equator. This picture contrasts with that obtained by Hochet et al. (2015) in the longwave and adiabatic limits. Their study, based on observations, shows unstable regions concentrated in the tropics with much weaker instability from middle to subpolar latitudes. When the longwave approximation is used, our calculations are in better agreement with Hochet et al. (2015) and indicate stronger growth rates over the tropical band. However instability still occurs poleward although it is reduced in large parts of the subpolar gyre (not shown). The consideration of horizontal Laplacian viscosity (Fig. 13b) does not alter this picture, but simply decreases the growth rates and increases the horizontal scale of the most unstable modes. 
An estimation of the growth of baroclinic waves in the presence of viscosity can be obtained by assuming a balance between the lhs of (3a) and the viscous term on the rhs, leading to $\omega_{i}=\nu_{h} R_{i}^{2} K^{4}(h / H)^{2}$, where $R_{i}=N H / f$ is the internal Rossby radius, and $h$ is a vertical scale of perturbations. This readily shows that the gravest modes, for which $h / H=O(1)$, are favored by the instability when viscosity is present. Assuming now that the growth rate $\omega_{i}$ be scaled as $K_{m} \hat{U}$, where $K_{m}$ is the wavenumber maximizing the growth rate and $\hat{U}$ is a horizontal velocity scale, the horizontal scale of the most unstable wave varies as $2 \pi\left(\nu_{h} R_{i}^{2} / \hat{U}\right)^{1 / 3}$. For typical midlatitude values $\hat{U}=1 \mathrm{~cm} \mathrm{~s}^{-1}, R_{i}=12 \mathrm{~km}$ (averaged Rossby radius in the region of propagation), and $\nu_{h}=$ $5 \times 10^{4} \mathrm{~m}^{2} \mathrm{~s}^{-1}$ (the value used in the model), a horizontal scale of $560 \mathrm{~km}$ emerges. This value is about $30 \%$ lower than the scale of SST anomalies shown in Fig. 9 $(800 \mathrm{~km})$. The difference may be due to turbulent eddy diffusion that tends to increase the scale of anomalies (as will be shown below), an effect that has been ignored in the present scaling analysis. The associated growth rate is $3.4 \mathrm{yr}^{-1}$, in good agreement with Fig. 13b, and is much smaller than those usually found at the eddy scale. These results suggest that lateral viscosity plays a dominant role in setting the growth and horizontal scale of SST anomalies in the model. The same conclusions were reached by Colin de Verdière (1986) in the planetary geostrophic limit.

Adding vertical viscosity (Fig. 13c) has a negligible impact, consistent with $(K h)^{-2} \nu_{v} / \nu_{h} \ll 1$. Adding turbulent horizontal diffusivity $\left(k_{h}=500 \mathrm{~m}^{2} \mathrm{~s}^{-1}\right.$; Fig. 13d) further reduces growth rates in large parts of the North Atlantic. The effect of vertical diffusivity (Fig. 13e) is by contrast substantial and drastically reduces growth rates in large parts of the subpolar area: unstable modes with strong vertical shears (shear scales $h \ll\left(k_{v} / \omega_{i}\right)^{1 / 2}$, about $50 \mathrm{~m}$ for $k_{v}=10^{-4} \mathrm{~m}^{2} \mathrm{~s}^{-1}$ and $\omega_{i}=1 \mathrm{yr}^{-1}$ ) are efficiently suppressed by vertical mixing. See also Fig. 14 for an illustration of the effect of vertical diffusivity at a specific location. When convective mixing is also included (Fig. 13f), unstable modes subsisting near the equator and in the East Greenland Current are suppressed.

The largest growths are found along the western boundary current with a typical horizontal scale of $O(1000) \mathrm{km}$ (not shown), which is much larger than the distance separating these modes from the coast. It is thus expected that side boundary effects will have a large influence. Since these effects have not been included in our calculations, these western boundary unstable modes become irrelevant. We are thus left with the only unstable region identified by the method, which lies in the western part of the subpolar gyre, just to the east of Newfoundland. This site roughly coincides with that

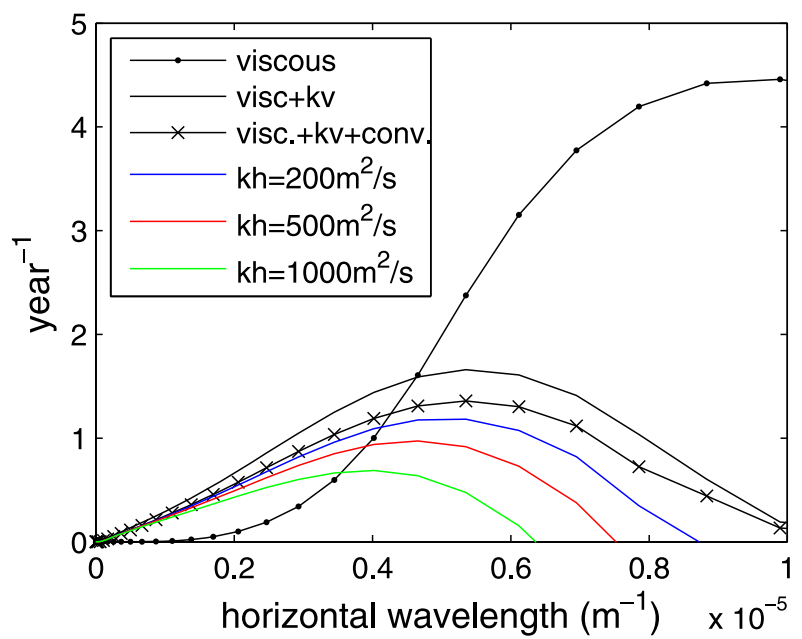

FIG. 14. Growth rate as a function of horizontal wavenumber at the specific location $47^{\circ} \mathrm{N}, 40^{\circ} \mathrm{W}$ in the western part of the subpolar gyre. The different curves correspond to different sets of mixing parameters: $\nu_{h}=5 \times 10^{4} \mathrm{~m} 2 \mathrm{~s}^{-1}$ (black line with dots), same but with $k_{v}$ following a Bryan-Lewis vertical profile (black line), same but with convective mixing (black line with crosses), and same but with $k_{h}=200$ (blue), 500 (red), and $1000 \mathrm{~m}^{2} \mathrm{~s}^{-1}$ (green).

where the variability peaks in the model. The growth of baroclinic waves is $O(1) \mathrm{yr}^{-1}$ with a horizontal scale of $O(1000) \mathrm{km}$ (Fig. 14).

\section{Summary and discussion}

The objective of this paper was to test the hypothesis that internal generation of interdecadal variability of the ocean circulation may be relevant to explain North Atlantic climate variability. This work is an extension of previous studies that identified a robust internal ocean mode in a hierarchy of idealized configurations and models. Here the robustness of this mode has been assessed in a realistic ocean model at $1^{\circ}$ horizontal resolution under prescribed surface fluxes. Both the numerical experiments and the diagnostic tools were designed to unravel both the phenomenology and the origin of the variability. The dependence of the ocean mode upon turbulent eddy diffusivities (isopycnal mixing $K$ and eddy-induced diffusivity $K_{\mathrm{GM}}$ ) was also explored.

The main result of this study is the robustness of the mechanism identified earlier in idealized box-ocean models forced by prescribed surface buoyancy fluxes (Colin de Verdière and Huck 1999; te Raa and Dijkstra 2002). The bifurcation structure of the variability, its spatial pattern, the temporal evolution of SST anomalies, and the energy sources and instability mechanism driving the variability are recovered here in a more realistic setting, showing the value of the idealized box-ocean 
models for inferring generic physical processes in the context of internal variability of the North Atlantic circulation.

The strength and existence of the internal variability in the model is sensitive to eddy-induced turbulent diffusivity $K_{\mathrm{GM}}$ and isopycnal mixing $K$. The transition from steady solutions to oscillatory ones is shown to be consistent with a supercritical Hopf bifurcation with the eddy-induced Peclet number $U L / K_{\mathrm{GM}}$ as the critical parameter. Such a behavior was recognized quite early in idealized ocean models forced by prescribed surface fluxes or coupled to energy-balanced models with the horizontal turbulent diffusivity and the inverse of the heat exchange coefficients as control parameters, respectively (Chen and Ghil 1996; Colin de Verdière and Huck 1999). In the present case, the variability disappears for $K_{\mathrm{GM}}>600 \mathrm{~m}^{2} \mathrm{~s}^{-1}$ (keeping $K=1000 \mathrm{~m}^{2} \mathrm{~s}^{-1}$ ). This critical value is much smaller than typical eddyinduced diffusivities used in realistic coupled models, suggesting that atmospheric stochastic forcing will be needed for these internal ocean modes to emerge.

The variability is caused by a linear instability of the mean circulation and stratification as evidenced by the evolution of the perturbations upon the switch from surface restoring to flux boundary conditions. The mechanism relies on a (large scale) baroclinic instability of the North Atlantic Current at subpolar latitudes, which radiates long baroclinic planetary waves that grow on the mean potential vorticity gradient. This view is supported by a local linear stability calculation including both viscous and diffusive effects that demonstrates the baroclinically unstable character of the NAC on horizontal scales of $O(1000) \mathrm{km}$ with growth rates of $O(1) \mathrm{yr}^{-1}$. Despite its inherent limitations, the results from the linear stability analysis appear in strikingly good agreement with the location of interdecadal perturbations when all the dissipative processes of the nonlinear model are taken into account.

Specific features include a westward propagation of relatively strong SST anomalies west of the NAC and a one-quarter phase lag between upper and subsurface $(800 \mathrm{~m})$ temperature anomalies in the unstable region. The same features have been inferred from observations (Feng and Dijkstra 2014; Frankcombe et al. 2008). Eastward propagation of weaker SST signals is obtained east of the NAC. Additional experiments including relatively strong surface restoring east of the NAC but not detailed in this study demonstrate that these eastwardpropagating waves are not essential to the existence of the variability and can therefore be interpreted as a consequence rather than a cause of the variability. The horizontal structure of the mode is characterized by a dipole of SST anomalies in the subpolar area, with the first two EOFs explaining between $40 \%$ and $90 \%$ of the total integrated variance depending on turbulent eddy diffusivities. SST variability in the other parts of the North Atlantic is totally absent, including in the tropical area. This suggests that intrinsic ocean circulation variability does not participate to the observed AMO signature in this area. Instead, thermal coupling with the atmosphere must be invoked (Xie 1999). The period of the variability is $O(20) \mathrm{yr}$ at bifurcation and decreases down to $O(10)$ yr for the smallest $K_{\mathrm{GM}}$ used here. A number of observations based on different methods around the North Atlantic also underline the existence of such a bidecadal time scale (Plaut et al. 1995; Frankcombe and Dijkstra 2009; Chylek et al. 2011).

There are obvious drawbacks associated with the model configuration used in this study. The absence of mesoscale turbulence and the lack of a proper representation of ocean-atmosphere coupling are all factors that certainly participate to reduce the realism of the simulated North Atlantic circulation and variability. Perhaps the main shortcoming of the mean circulation concerns the mean path of the North Atlantic Current that is too far to the west compared to observations, a well-known problem in low-resolution OGCMs (Denng et al. 1996; Zhang and Vallis 2007). The pathway of the Gulf Stream and the NAC could eventually be made more realistic in such coarse-resolution ocean models when $K_{\mathrm{GM}}$ becomes vertically dependent (Eden et al. 2009), as opposed to the Visbeck et al. (1997) formulation that assumes a vertically constant coefficient. The impact that this choice of the GM scheme might have on the variability remains to be studied. Corrections of the NAC in a coupled model increases the realism of the spatial pattern of the AMO (Drews and Greatbatch 2016). The region of maximum SST variability in their flux-corrected coupled simulations appears to be in the northwestern corner of the Atlantic basin, just to the east of Newfoundland, as in observations (Deser et al. 2010). Despite this bias, our model simulations also reveal maximum SST variance in this region, a central region where unstable long baroclinic planetary waves draw their energy from the mean flow.

At the coarse resolution used here, mesoscale eddies are parameterized rather than resolved. Huck et al. (2015) demonstrated than the basic mechanism driving the interdecadal variability under flux boundary conditions in idealized geometry ocean models is robust in the presence of mesoscale turbulence. In particular the coherence of the large-scale SST and SSH anomalies during their westward propagation and the $O(20-30)$-yr period are maintained from coarse to eddy-resolving simulations. The flux boundary conditions used here 
tend to maximize the growth rate of perturbations. This probably makes the amplitude of the variability larger than it would be if more realistic boundary conditions, including at least the damping effect of air-sea turbulent heat fluxes, were considered. We show that adding thermal damping with a time scale of $1 \mathrm{yr}$, typical of that deduced from energy-balance models (Vallis 2009), displaces the domain of existence of oscillations toward slightly higher Peclet numbers (lower $K_{\mathrm{GM}}$ values), without significantly changing the bifurcation structure.

The intrinsic oceanic mode described here has also the same characteristics as the one obtained by Sévellec and Fedorov (2013). These authors used a linear tangent and adjoint technique to identify the least damped oceanic eigenmode in a realistic configuration of the OPA model at a lower $2^{\circ}$ horizontal resolution. The major difference between the two studies is the selfsustained character of the oscillations found here as opposed to the damped character (over a 40-yr time scale) of interdecadal oscillations in Sévellec and Fedorov (2013). This mode may eventually be sustained in coupled simulations (Ortega et al. 2015; Muir and Fedorov 2017) but the precise role of the NAO, air-sea coupling, and the Nordic seas overflows is still uncertain (Delworth and Greatbatch 2000; Dai et al. 2005; Dong and Sutton 2005; Danabasoglu 2008; Danabasoglu et al. 2012; Tulloch and Marshall 2012; Kwon and Frankignoul 2012).

The internal oceanic mode presented here is robust across a hierarchy of ocean models and shares many similarities with observations, in particular the westward propagation and vertical phase lag of perturbations at subpolar latitudes (Frankcombe et al. 2008; Feng and Dijkstra 2014; Chylek et al. 2011). These similarities indicate that a leading role of the ocean for the AMO cannot be ruled out. This stresses the need for continued effort to improve understanding of intrinsic lowfrequency ocean variability. Not considered in this study is the atmospheric stochastic forcing that has been recognized as a strong paradigm for low-frequency climate variability. This weather noise affects the behavior of the coupled system through both thermodynamical (Hasselmann 1976) and dynamical (Frankcombe and Dijkstra 2009) processes. This paper has shown that ocean dynamics alone is sufficient to reproduce the observed maximum of SST variance in the subpolar area. A natural question is, therefore, to ask how the ocean response to atmospheric stochastic forcing is affected by the presence of this internal oceanic mode, and in particular how it differs from the pure thermodynamical response of slab oceans put forward by Clement et al. (2015).
Acknowledgments. This study was supported by the CNRS French national program LEFE/INSU. We thank two anonymous reviewers for their comments and suggestions, which helped to improve the manuscript. Numerical computations were conducted using the Pôle de Calcul Intensif pour la Mer at Ifremer, Brest, France. We thank the MITgcm development group for making their model freely available.

\section{REFERENCES}

Amante, C., and B. W. Eakins, 2009: ETOPO1 1 arc-minute global relief model: Procedures, data sources, and analysis. NOAA Tech. Memo. NESDIS NGDC-24, 25 pp., https://www.ngdc.noaa.gov/ $\mathrm{mgg} / \mathrm{global} / \mathrm{relief} / \mathrm{ETOPO1/docs/ETOPO1.pdf.}$

Antonov, J. I., and Coauthors, 2010: Salinity. Vol. 2, World Ocean Atlas 2009, NOAA Atlas NESDIS 69, 184 pp.

Arzel, O., and A. Colin de Verdière, 2016: Can we infer diapycnal mixing rates from the World Ocean temperature-salinity distribution? J. Phys. Oceanogr., 46, 3751-3775, https://doi.org/ 10.1175/JPO-D-16-0152.1.

, T. Huck, and A. Colin de Verdière, 2006: The different nature of the interdecadal variability of the thermohaline circulation under mixed and flux boundary conditions. J. Phys. Oceanogr., 36, 1703-1718, https://doi.org/ 10.1175/JPO2938.1.

, A. Colin de Verdière, and T. Huck, 2007: On the origin of interdecadal oscillations in a coupled ocean-atmosphere model. Tellus, 59A, 367-383, https://doi.org/10.1111/ j.1600-0870.2007.00227.x.

, M. H. England, A. Colin de Verdière, and T. Huck, 2012: Abrupt millennial variability and interdecadal-interstadial oscillations in a global coupled model: Sensitivity to the background climate state. Climate Dyn., 39, 259-275, https:// doi.org/10.1007/s00382-011-1117-y.

Barsugli, J. J., and D. S. Battisti, 1998: The basic effects of atmosphere-ocean thermal coupling on midlatitude variability. J. Atmos. Sci., 55, 477-493, https://doi.org/10.1175/ 1520-0469(1998)055<0477:TBEOAO > 2.0.CO;2.

Bryan, K., and L. J. Lewis, 1979: A water mass model of the World Ocean. J. Geophys. Res., 84, 2503-2517, https://doi.org/ 10.1029/JC084iC05p02503.

Buckley, M. W., D. Ferreira, J.-M. Campin, J. Marshall, and R. Tulloch, 2012: On the relationship between decadal buoyancy anomalies and variability of the Atlantic meridional overturning circulation. J. Climate, 25, 8009-8030, https://doi.org/ 10.1175/JCLI-D-11-00505.1.

Cane, M. A., A. C. Clement, L. N. Murphy, and K. Bellomo, 2017: Low-pass filtering, heat flux, and Atlantic multidecadal variability. J. Climate, 30, 7529-7553, https://doi.org/10.1175/ JCLI-D-16-0810.1.

Chen, F., and M. Ghil, 1996: Interdecadal variability in a hybrid coupled ocean-atmosphere model. J. Phys. Oceanogr., 26, 1561-1578, https://doi.org/10.1175/1520-0485(1996)026<1561: IVIAHC $>2.0 . \mathrm{CO} ; 2$.

Cheng, W., R. Bleck, and C. Rooth, 2004: Multi-decadal thermohaline variability in an ocean-atmosphere general circulation model. Climate Dyn., 22, 573-590, https://doi.org/10.1007/ s00382-004-0400-6.

Chylek, P., C. K. Folland, H. A. Dijkstra, G. Lesins, and M. K. Dubey, 2011: Ice-core data evidence for a prominent near 20 year 
time-scale of the Atlantic multidecadal oscillation. Geophys. Res. Lett., 38, L13704, https://doi.org/10.1029/2011GL047501.

Clement, A., K. Bellomo, L. N. Murphy, M. A. Cane, T. Mauritsen, G. Rädel, and B. Stevens, 2015: The Atlantic multidecadal oscillation without a role for ocean circulation. Science, 350, 320-324, https://doi.org/10.1126/science.aab3980.

Colin de Verdière, A., 1986: On mean flow instabilities within the planetary geostrophic equations. J. Phys. Oceanogr., 16, 1981-1984, https://doi.org/10.1175/1520-0485(1986)016<1981: OMFIWT>2.0.CO;2.

, and T. Huck, 1999: Baroclinic instability: An oceanic wavemaker for interdecadal variability. J. Phys. Oceanogr., 29, 893-910, https://doi.org/10.1175/1520-0485(1999)029<0893: BIAOWF $>2.0 . \mathrm{CO} ; 2$.

—_, and M. Ollitrault, 2016: A direct determination of the World Ocean barotropic circulation. J. Phys. Oceanogr., 46, 255-273, https://doi.org/10.1175/JPO-D-15-0046.1.

Dai, A., A. Hu, G. A. Meehl, W. M. Washington, and W. G. Strand, 2005: Atlantic thermohaline circulation in a coupled general circulation model: Unforced variations versus forced changes. J. Climate, 18, 3270-3293, https://doi.org/10.1175/JCLI3481.1; Corrigendum, 18, 4915-4918, https://doi.org/10.1175/JCLI9006.1.

Danabasoglu, G., 2008: On multidecadal variability of the Atlantic meridional overturning circulation in the Community Climate System Model version 3. J. Climate, 21, 5524-5544, https://doi.org/ 10.1175/2008JCLI2019.1; Corrigendum, 22, 1586, https://doi.org/ 10.1175/2008JCLI2986.1.

— S. G. Yeager, Y.-O. Kwon, J. J. Tribbia, A. S. Phillips, and J. W. Hurrel, 2012: Variability of the Atlantic meridional overturning circulation in CCSM4. J. Climate, 25, 5153-5172, https://doi.org/10.1175/JCLI-D-11-00463.1.

de Boyer Montégut, C., G. Madec, A. S. Fischer, A. Lazar, and D. Iudicone, 2004: Mixed layer depth over the global ocean: An examination of profile data and a profile-based climatology. J. Geophys. Res., 109, C12003, https://doi.org/10.1029/ 2004JC002378.

Delworth, T. L., and R. J. Greatbatch, 2000: Multidecadal thermohaline circulation variability excited by atmospheric surface flux forcing. J. Climate, 13, 1481-1495, https://doi.org/ 10.1175/1520-0442(2000)013<1481:MTCVDB > 2.0.CO;2.

, and F. Zeng, 2012: Multicentennial variability of the Atlantic meridional overturning circulation and its climatic influence in a 4000 year simulation of the GFDL CM2.1 climate model. Geophys. Res. Lett., 39, L13702, https://doi.org/10.1029/ 2012 GL052107.

—, R. Zhang, and M. E. Mann, 2007: Decadal to centennial variability of the Atlantic from observations and models. Ocean Circulation: Mechanisms and Impacts, Geophys. Monogr., Vol. 173, Amer. Geophys. Union, 131-148.

Denng, J., A. Beckmann, and R. Gerdes, 1996: The Gulf Stream separation problem. The Warmwatersphere of the North Atlantic Ocean, W. Krauss, Ed., Gebrüder Borntraeger, 253-290.

Deser, C., M. A. Alexander, S.-P. Xie, and A. S. Phillips, 2010: Sea surface temperature variability: Patterns and mechanisms. Annu. Rev. Mar. Sci., 2, 115-143, https://doi.org/10.1146/ annurev-marine-120408-151453.

Dommenget, D., and M. Latif, 2002: Analysis of observed and simulated SST spectra in the midlatitudes. Climate Dyn., 19, 277-288, https://doi.org/10.1007/s00382-002-0229-9.

Dong, B., and R. T. Sutton, 2005: Mechanism of interdecadal thermohaline circulation variability in a coupled oceanatmosphere GCM. J. Climate, 18, 1117-1135, https://doi.org/ 10.1175/JCLI3328.1.
Drews, A., and R. J. Greatbatch, 2016: Atlantic multidecadal variability in a model with an improved North Atlantic Current. Geophys. Res. Lett., 43, 8199-8206, https://doi.org/ 10.1002/2016GL069815.

Eden, C., M. Jochum, and G. Danabasoglu, 2009: Effects of different closures for thickness diffusivity. Ocean Modell., 26, 47 59, https://doi.org/10.1016/j.ocemod.2008.08.004.

Enfield, D. B., A. M. Mestas-Nuñez, and P. J. Trimble, 2001: The Atlantic multidecadal oscillation and its relation to rainfall and river flows in the continental U.S. Geophys. Res. Lett., 28 , 2077-2080, https://doi.org/10.1029/2000GL012745.

Feng, Q. Y., and H. Dijkstra, 2014: Are North Atlantic multidecadal SST anomalies westward propagating? Geophys. Res. Lett., 41, 541-546, https://doi.org/10.1002/2013GL058687.

Ferjani, D., T. Huck, and A. Colin de Verdière, 2013: Influence of bottom topography on large-scale decadal basin modes. J. Mar. Res., 71, 289-316, https://doi.org/10.1357/ 002224013808877080.

Frankcombe, L. M., and H. A. Dijkstra, 2009: Coherent multidecadal variability in North Atlantic sea level. Geophys. Res. Lett., 36, L15604, https://doi.org/10.1029/2009GL039455.

,,-- and A. von der Heydt, 2008: Sub-surface signatures of the Atlantic multidecadal oscillation. Geophys. Res. Lett., 35, L19602, https://doi.org/10.1029/2008GL034989.

,$- \ldots$, and,- 2009 : Noise-induced multidecadal variability in the North Atlantic: Excitation of normal modes. J. Phys. Oceanogr., 39, 220-233, https://doi.org/10.1175/ 2008JPO3951.1.

Frankignoul, C., E. Kestenare, M. Botzet, A. F. Carril, H. Drange, A. Pardaens, L. Terray, and R. Sutton, 2004: An intercomparison between the surface heat flux feedback in five coupled models, COADS and the NCEP reanalysis. Climate Dyn., 22, 373-388, https://doi.org/10.1007/s00382-003-0388-3.

Gent, P. R., and J. C. McWilliams, 1990: Isopycnal mixing in ocean circulation models. J. Phys. Oceanogr., 20, 150-155, https:// doi.org/10.1175/1520-0485(1990)020<0150:IMIOCM > 2.0.CO;2.

Greatbatch, R. J., and S. Zhang, 1995: An interdecadal oscillation in an idealized ocean basin forced by constant heat flux. J. Climate, 8, 81-91, https://doi.org/10.1175/1520-0442(1995)008<0081: AIOIAI $>2.0 . \mathrm{CO} ; 2$.

Griffies, S. M., R. C. Pacanowski, and R. W. Hallberg, 2000: Spurious diapycnal mixing associated with advection in a $z$-coordinate ocean model. Mon. Wea. Rev., 128, 538-564, https://doi.org/ 10.1175/1520-0493(2000)128<0538:SDMAWA > 2.0.CO;2.

Gulev, S. K., M. Latif, N. Keenlyside, W. Park, and K. P. Koltermann, 2013: North Atlantic Ocean control on surface heat flux on multidecadal timescales. Nature, 499, 464-467, https://doi.org/10.1038/nature12268.

Häkkinen, S., P. B. Rhines, and D. L. Worthen, 2013: Northern North Atlantic sea surface height and ocean heat content variability. J. Geophys. Res. Oceans, 118, 3670-3678, https:// doi.org/10.1002/jgrc.20268.

Hasselmann, K., 1976: Stochastic climate models. Part I: Theory. Tellus, 28, 473-485, https://doi.org/10.3402/tellusa.v28i6.11316.

Held, I. M., 2005: The gap between simulation and understanding in climate modeling. Bull. Amer. Meteor. Soc., 86, 1609-1614, https://doi.org/10.1175/BAMS-86-11-1609.

Herbaut, C., J. Sirven, and S. Février, 2002: Response of a simplified oceanic general circulation model to idealized NAO-like stochastic forcing. J. Phys. Oceanogr., 32, 3182-3192, https://oi.org/ 10.1175/1520-0485(2002)032<3182:ROASOG > 2.0.CO;2.

Hochet, A., T. Huck, and A. Colin de Verdière, 2015: Large-scale baroclinic instability of the mean oceanic circulation: A local 
approach. J. Phys. Oceanogr., 45, 2738-2754, https://doi.org/ 10.1175/JPO-D-15-0084.1.

Huck, T., and G. K. Vallis, 2001: Linear stability analysis of the three-dimensional thermally-driven ocean circulation: Application to interdecadal oscillations. Tellus, 53A, 526-545, https://doi.org/10.3402/tellusa.v53i4.12225.

— , A. Colin de Verdière, and A. J. Weaver, 1999: Interdecadal variability of the thermohaline circulation in box-ocean models forced by fixed surface fluxes. J. Phys. Oceanogr., 29, 865-892, https://doi.org/10.1175/1520-0485(1999)029<0865: IVOTTC $>2.0 . \mathrm{CO} ; 2$

_ - G. K. Vallis, and A. Colin de Verdière, 2001: On the robustness of the interdecadal modes of the thermohaline circulation. J. Climate, 14, 940-963, https://doi.org/10.1175/ 1520-0442(2001)014<0940:OTROTI > 2.0.CO;2.

—, O. Arzel, and F. Sévellec, 2015: Multidecadal variability of the overturning circulation in presence of eddy turbulence. J. Phys. Oceanogr., 45, 157-173, https://doi.org/10.1175/JPO-D-14-0114.1.

Jackett, D. R., and T. J. McDougall, 1995: Minimal adjustment of hydrographic profiles to achieve static stability. J. Atmos. Oceanic Technol., 12, 381-389, https://doi.org/10.1175/ 1520-0426(1995)012<0381:MAOHPT>2.0.CO;2.

Jamet, Q., T. Huck, O. Arzel, J.-M. Campin, and A. Colin de Verdière, 2016: Oceanic control of multidecadal variability in an idealized coupled GCM. Climate Dyn., 46, 3079-3095, https://doi.org/10.1007/s00382-015-2754-3.

Knight, J. R., 2009: The Atlantic multidecadal oscillation inferred from the forced climate response in coupled general circulation models. J. Climate, 22, 1610-1625, https://doi.org/10.1175/ 2008JCLI2628.1.

— C. K. Folland, and A. A. Scaife, 2006: Climate impacts of the Atlantic multidecadal oscillation. Geophys. Res. Lett., 33, L17706, https://doi.org/10.1029/2006GL026242.

Knudsen, M. F., M.-S. Seidenkrantz, B. H. Jacobsen, and A. Kuijpers, 2011: Tracking the Atlantic multidecadal oscillation through the last 8,000 years. Nat. Commun., 2, 178, https://doi.org/10.1038/ncomms1186.

Kushnir, Y., 1994: Interdecadal variations in North Atlantic sea surface temperature and associated atmospheric conditions. J. Climate, 7, 141-157, https://doi.org/10.1175/1520-0442(1994)007<0141: IVINAS $>2.0 . \mathrm{CO} ; 2$.

Kwon, Y.-O., and C. Frankignoul, 2012: Stochastically-driven multidecadal variability of the Atlantic meridional overturning circulation in CCSM3. Climate Dyn., 38, 859-876, https://doi.org/10.1007/s00382-011-1040-2.

Large, W. G., and S. G. Yeager, 2009: The global climatology of an interannually varying air-sea flux data set. Climate Dyn., 33, 341-364, https://doi.org/10.1007/s00382-008-0441-3.

Locarnini, R. A., A. V. Mishonov, J. I. Antonov, T. P. Boyer, H. E. Garcia, O. K. Baranova, M. M. Zweng, and D. R. Johnson, 2010: Temperature. Vol. 1, World Ocean Atlas 2009, NOAA Atlas NESDIS 68, $184 \mathrm{pp}$.

Lumpkin, R., and K. Speer, 2007: Global ocean meridional overturning. J. Phys. Oceanogr., 37, 2550-2562, https://doi.org/ 10.1175/JPO3130.1.

Marshall, J., A. Adcroft, C. Hill, L. Perelman, and C. Heisey, 1997: A finite-volume, incompressible Navier Stokes model for studies of the ocean on parallel computers. J. Geophys. Res., 102, 5753-5766, https://doi.org/10.1029/96JC02775.

, J. R. Scott, A. Romanou, M. Kelley, and A. Leboissetier, 2017: The dependence of the ocean's MOC on mesoscale eddy diffusivities: A model study. Ocean Modell., 111, 1-8, https:// doi.org/10.1016/j.ocemod.2017.01.001.
McDougall, T. J., and P. M. Barker, 2011: Getting started with TEOS-10 and the Gibbs Seawater (GSW) oceanographic toolbox. Scientific Committee on Oceanic Research-IAPSO Rep. WG127, 28 pp.

Muir, L. C., and A. V. Fedorov, 2017: Evidence for the AMOC interdecadal mode related to westward propagation of temperature anomalies in CMIP5 models. Climate Dyn., 48, 15171535, https://doi.org/10.1007/s00382-016-3157-9.

O'Kane, T. J., R. J. Matear, M. A. Chamberlain, J. S. Risbey, B. M. Sloyan, and I. Horenko, 2013: Decadal variability in an OGCM Southern Ocean: Intrinsic modes, forced modes and metastable states. Ocean Modell., 69, 1-21, https://doi.org/ 10.1016/j.ocemod.2013.04.009.

O'Reilly, C. H., M. Huber, T. Woollings, and L. Zanna, 2016: The signature of low-frequency oceanic forcing in the Atlantic multidecadal oscillation. Geophys. Res. Lett., 43, 2810-2818, https://doi.org/10.1002/2016GL067925.

Ortega, P., J. Mignot, D. Swingedouw, F. Sévellec, and E. Guilyardi, 2015: Reconciling two alternative mechanisms behind bidecadal variability in the North Atlantic. Prog. Oceanogr., 137, 237-249, https://doi.org/10.1016/j.pocean.2015.06.009.

Pedlosky, J., 1987: Geophysical Fluid Dynamics. 2nd ed. SpringerVerlag, $710 \mathrm{pp}$.

Plaut, G., M. Ghil, and R. Vautard, 1995: Interannual and interdecadal variability in 335 years of central England temperature. Science, 268, 710-713, https://doi.org/10.1126/ science.268.5211.710.

Redi, M. H., 1982: Oceanic isopycnal mixing by coordinate rotation. J. Phys. Oceanogr., 12, 1154-1158, https://doi.org/ 10.1175/1520-0485(1982)012<1154:OIMBCR > 2.0.CO;2.

Schlesinger, M. E., and N. Ramankutty, 1994: An oscillation in the global climate system of period 65-70 years. Nature, 367, 723726, https://doi.org/10.1038/367723a0.

Sévellec, F., and A. V. Fedorov, 2013: The leading, interdecadal eigenmode of the Atlantic meridional overturning circulation in a realistic ocean model. J. Climate, 26, 2160-2183, https:// doi.org/10.1175/JCLI-D-11-00023.1.

, T. Huck, and M. B. Jelloul, 2006: On the mechanism of centennial thermohaline oscillations. J. Mar. Res., 64, 355-392, https://doi.org/10.1357/002224006778189608.

Smith, K. S., 2007: The geography of linear baroclinic instability in Earth's oceans. J. Mar. Res., 65, 655-683, https://doi.org/ $10.1357 / 002224007783649484$.

te Raa, L. A., and H. A. Dijkstra, 2002: Instability of the thermohaline circulation on interdecadal timescales. J. Phys. Oceanogr., 32, 138-160, https://doi.org/10.1175/1520-0485(2002)032<0138: IOTTOC $>2.0 . \mathrm{CO} ; 2$.

— J. Gerrits, and H. A. Dijkstra, 2004: Identification of the mechanism of interdecadal variability in the North Atlantic Ocean. J. Phys. Oceanogr., 34, 2792-2807, https://doi.org/ 10.1175/JPO2655.1.

Timmermann, A., M. Latif, R. Voss, and A. Grötzner, 1998: Northern Hemispheric interdecadal variability: A coupled air-sea mode. J. Climate, 11, 1906-1931, https://doi.org/ 10.1175/1520-0442-11.8.1906.

Tulloch, R., and J. Marshall, 2012: Exploring mechanisms of variability and predictability of Atlantic meridional overturning circulation in two coupled climate models. J. Climate, 25, 4067-4080, https://doi.org/10.1175/JCLI-D-11-00460.1.

,,- , and K. S. Smith, 2009:Interpretation of the propagation of surface altimetric observations in terms of planetary waves and geostrophic turbulence. J. Geophys. Res., 114, C02005, https://doi.org/10.1029/2008JC005055. 
C. Hill, and K. S. Smith, 2011: Scales, growth rates, and spectral fluxes of baroclinic instability in the ocean. J. Phys. Oceanogr., 41, 1057-1076, https://doi.org/10.1175/ 2011JPO4404.1.

Vallis, G. K., 2009: Mechanisms of climate variability from years to decades. Stochastic Physics and Climate Modelling, T. Palmer and P. Williams, Eds., Cambridge University Press, 1-33.

Veronis, G., 1975: The role of models in tracer studies. Numerical Models of the Ocean Circulation, National Academy of Science, 133-146.

Visbeck, M., J. Marshall, T. Haine, and M. Spall, 1997: Specification of eddy transfer coefficients in coarse-resolution ocean circulation models. J. Phys. Oceanogr., 27, 381-402, https://doi.org/ 10.1175/1520-0485(1997)027<0381:SOETCI $>2.0 . C O ; 2$.

Waterhouse, A. F., and Coauthors, 2014: Global patterns of diapycnal mixing from measurements of the turbulent dissipation rate. J. Phys. Oceanogr., 44, 1854-1872, https://doi.org/10.1175/ JPO-D-13-0104.1.

Winton, M., 1997: The damping effect of bottom topography on internal decadal-scale oscillations of the thermohaline circulation. J. Phys. Oceanogr., 27, 203-208, https://doi.org/10.1175/ 1520-0485(1997)027<0203:TDEOBT>2.0.CO;2.
Wolfe, C. L., P. Cessi, and B. D. Cornuelle, 2017: An intrinsic mode of interannual variability in the Indian Ocean. J. Phys. Oceanogr., 47, 701-719, https://doi.org/10.1175/JPO-D-16-0177.1.

Xie, S.-P., 1999: A dynamic ocean-atmosphere model of the tropical Atlantic decadal variability. J. Climate, 12, 64-70, https://doi.org/10.1175/1520-0442-12.1.64.

Zhang, R., 2017: On the persistence and coherence of subpolar sea surface temperature and salinity anomalies associated with the Atlantic multidecadal oscillation. Geophys. Res. Lett., 44, 7865-7875, https://doi.org/10.1002/2017GL074342.

, and G. K. Vallis, 2007: The role of bottom vortex stretching on the path of the North Atlantic western boundary current and on the northern recirculation gyre. J. Phys. Oceanogr., 37, 2053-2080, https://doi.org/10.1175/JPO3102.1.

_, R. Sutton, G. Danabasoglu, T. L. Delworth, W. M. Kim, J. Robson, and S. G. Yeager, 2016: Comment on "The Atlantic multidecadal oscillation without a role for ocean circulation.' Science, 352, 1527, https://doi.org/10.1126/science.aaf1660.

Zhu, X., and J. Jungclaus, 2008: Interdecadal variability of the meridional overturning circulation as an ocean internal mode. Climate Dyn., 31, 731-741, https://doi.org/10.1007/ s00382-008-0383-9. 